Journal of Educational

and Psychological Sciences

Volume (5), Issue (49): 30 Dec 2021

P: 90 - 108

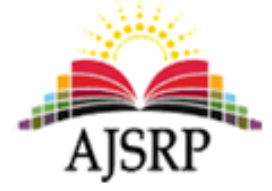

ISSN: 2522-3399

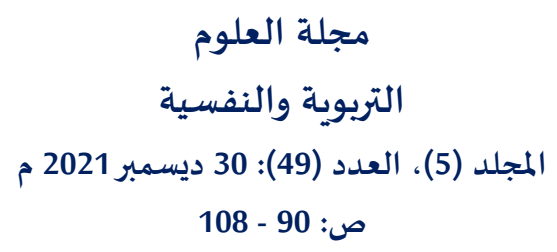

مجله العلوم

\title{
The Degree of school Principals Acquiring of educational technology competencies and its relation to teacher application of education technology from teacher point of view
}

\section{Kawthar Mohammad Rasheed Banisaeed}

Ministry of Education || Jordan

\begin{abstract}
This study aimed to identify the degree of school principals acquiring of educational technology competencies and its relation to teacher implementation of education technology from teachers point of view, the study used the descriptive analysis correlative approach, two questionnaires were development first one consisted from (20) paragraph, to determine the school principals acquiring of educational technology competencies, the second also consisted from (20) paragraph to determine the teacher implementation of education technology, the sample of study consisted from (340) female and male teacher. However, the finding of study showed that the school principals acquiring of educational technology competencies from teacher point of view was average and the teacher implementation of education technology from teacher point of view was also average, the finding also showed there was a statistically significant relationship between the school principals acquiring of educational technology competencies and teacher implementation of them at the level of $(\alpha \leq 0.05)$. In addition, the finding showed there wasn't any significant relation in the degree of school principals acquiring of educational technology competencies from teacher point of view refers to variable of teacher's sex.
\end{abstract}

Furthermore, there were significant differences at $(\alpha \leq 0.05)$ according to teacher qualification for higher education

Keywords: educational technology competencies, school principals, Ajloun Directorate.

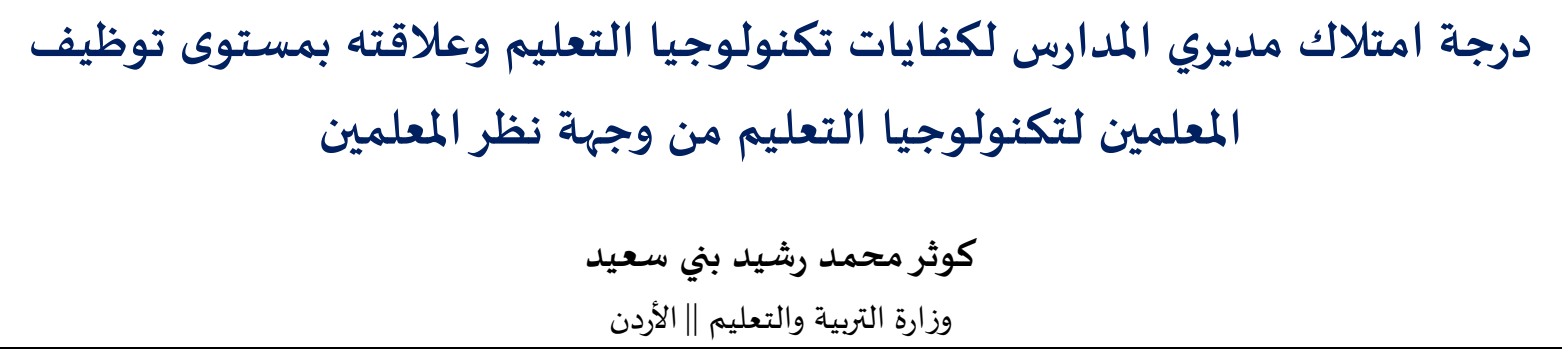

المستخلص: هدفت الدراسة الحالية إلى التعرف على درجة امتلاك مديري المدارس لكفايات تكنولوجيا التعليم وعلاقته بمستوى

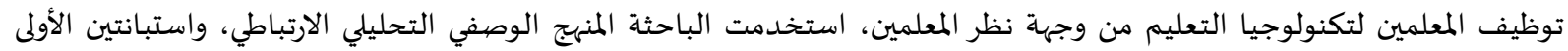
مكونة من (20) عبارة وهدفت إلى تعرف درجة امتلاك مديري المدارس لكفايات تكنولوجيا التعليم، وتكونت الاستبانة الثانية من (20) عبارة هدفت التعرف على مستوى توظيف المعلمين لتكنولوجيا التعليم في العلمية التعليمية، ، وتكونت عينة الدراسة من من (340) معلما ومعلمة، وقد أظهرت نتائج الدراسة أن درجة امتلاك مديري المدارس لكفايات تكنولوجيا التعليم من وجهة نظر المعلمين جاءت بدرجة مداء

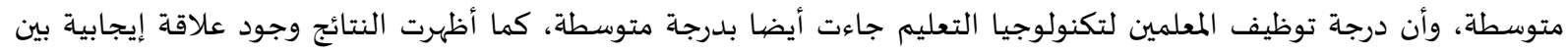

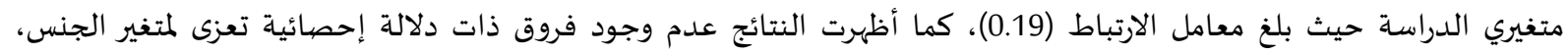

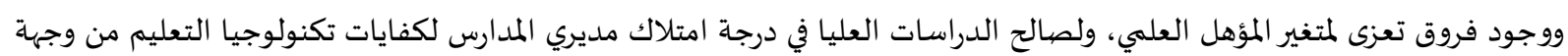
نظر المعلمين. 
أدى الانفجار المعرفي والتقدم العلمي والتكنولوجي المتسارع في هذا العصر إلى تغيرات جذرية شملت جميع

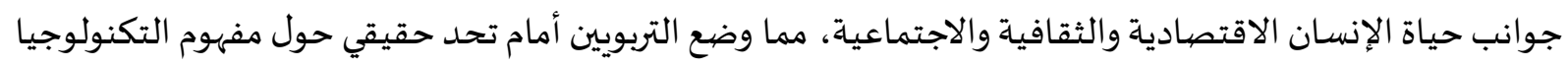

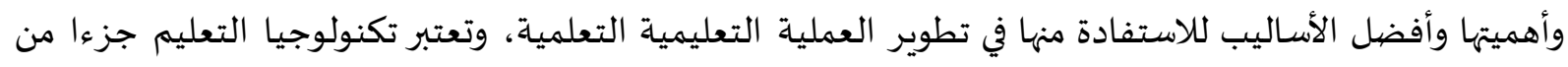

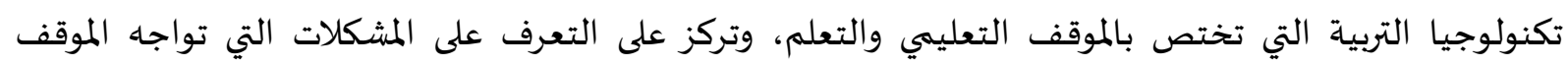

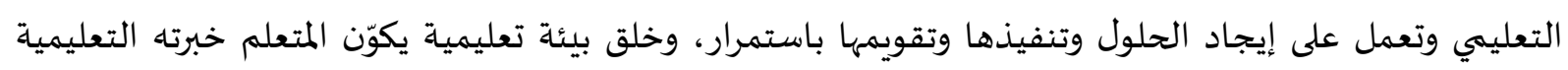

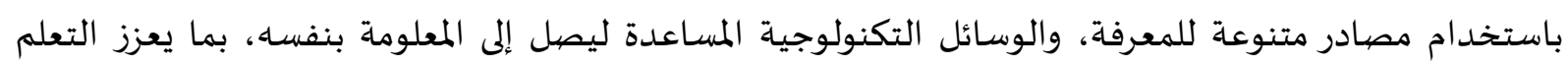
الذاتي لدى المتعلمين.

وتقع على عاتق مدير المدرسة واجبات كثيرة ومسؤوليات كبيرة ومتنوعة إدارية وتعليمية، وواجبات تربوية

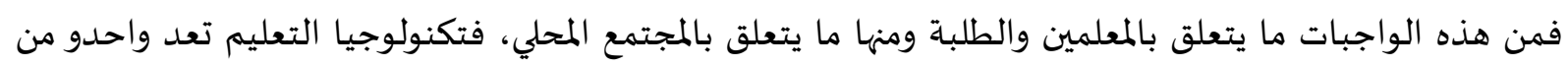

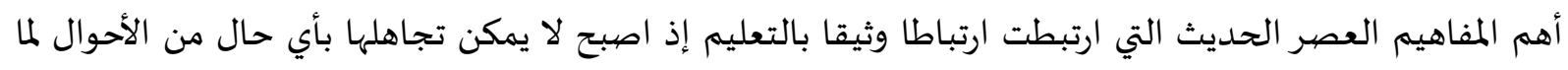

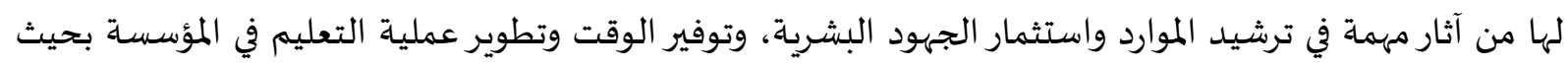

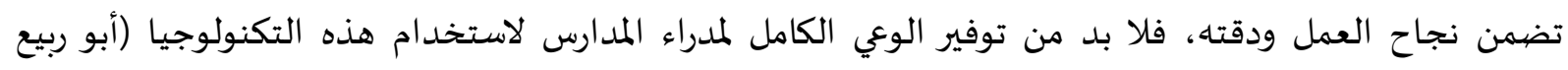
والشرمان، 2015).

وتسهم تكنولوجيا المعلومات في تصميم المواقف التعليمية وتقدم المساندة للمعلم، في أداء عمله وتكوين

علاقة إيجابية بين المعلم والطالب كما تسهم في عمليات التخطيط والقياس والتقويم التربوي (شحادة، 2010). وفي ضوء هذه التطورات والتغيرات لم يعد دور مدير المدرسة مقتصرًا على القيام بالأعمال الإدارية

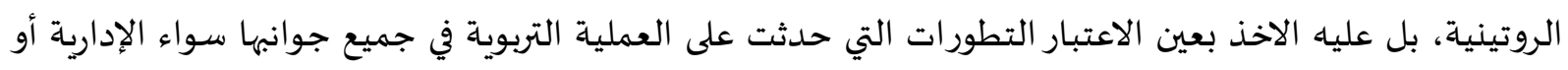

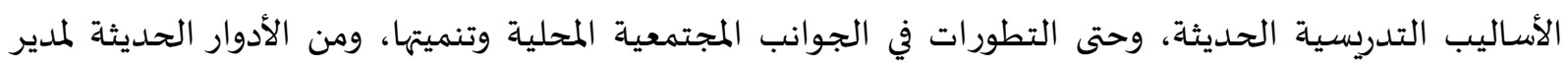

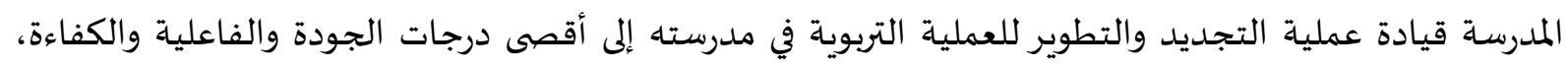

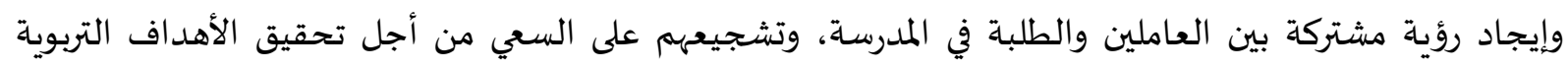

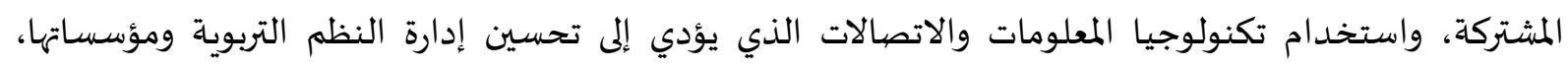

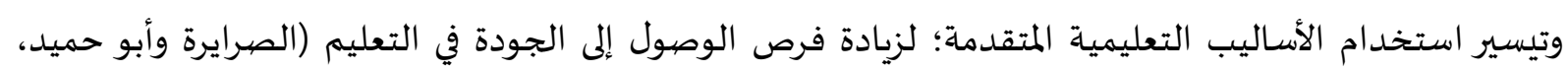

وتعد الإدارة المدرسية نواة التشكيل الإداري في النظام التعليمي؛ إذ يقع على عاتقها تنفيذ السياسـة

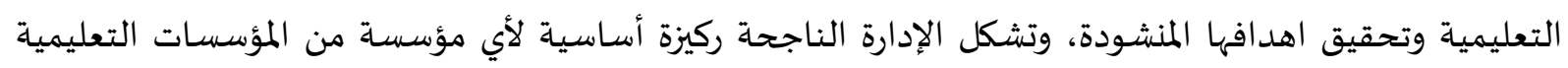

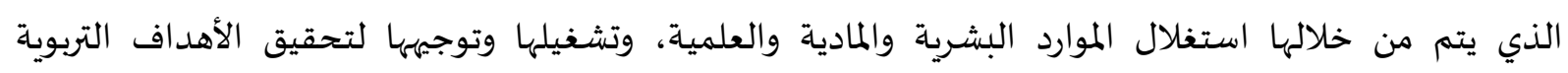

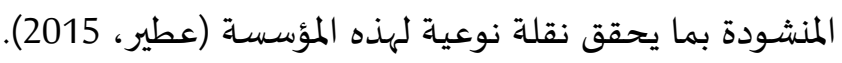

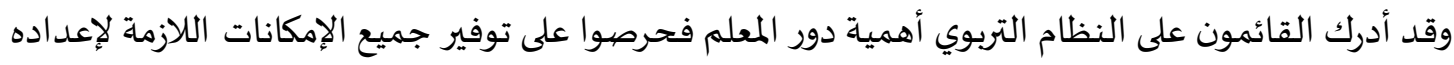

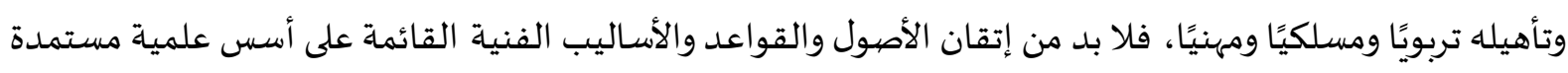

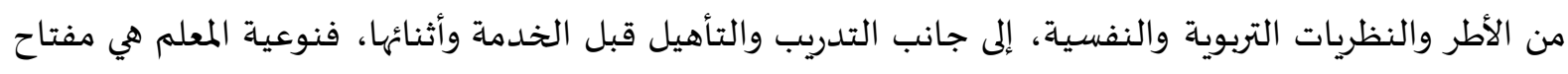

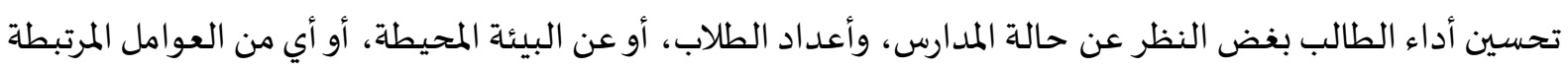


بحياة الطالب في بيئة التعلم والتعليم، وبالرغم من أهمية هذه العناصر كلها فإنها تبقى محدودة الفائدة ما لم يتوافر

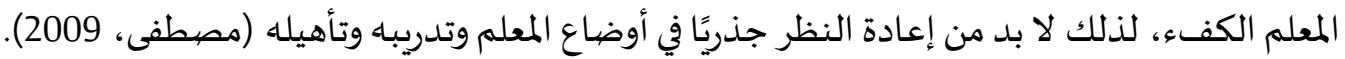

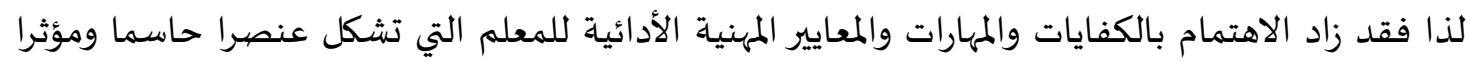

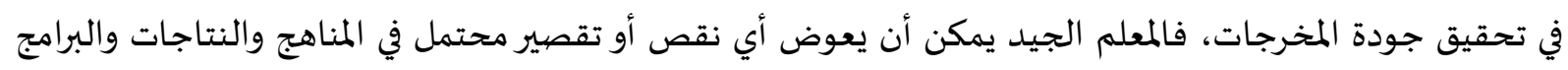

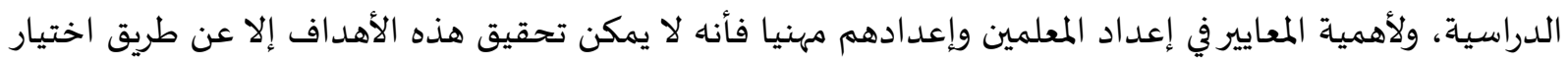

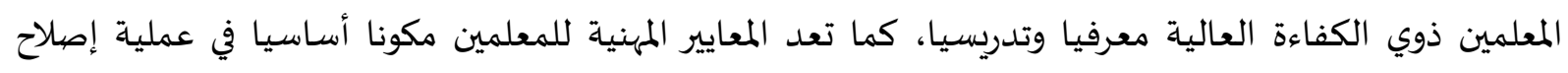

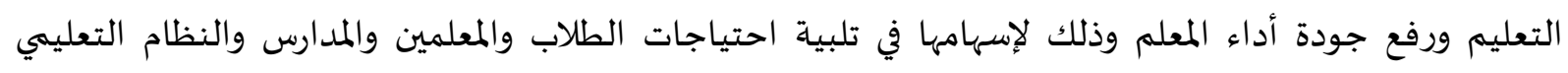
بأكمله (المومني والسعايده، 2018).

مشكلة الدراسـة

أظهرت نتائج بعض الدراسات السابقة أهمية استخدام تكنولوجيا المعلومات والاتصالات في العملية التعليمية، حيث تساعد على تحسين مستوى الطلبة عن طريق نقل المعارف لهم بكل سهولة ويسر، وقدرتها على

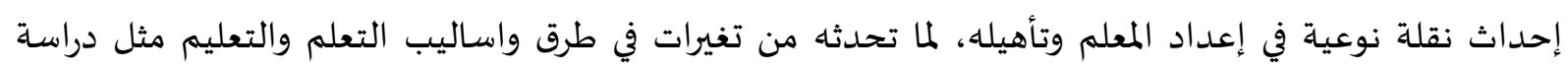
البادي (2020) ودراسة (Ira et al, 2019). والأردن كباقي دول العالم يؤمن بأن التعليم هو اساس النهضة والرقي والتقدم في كافة المجالات، ويسعى دوما

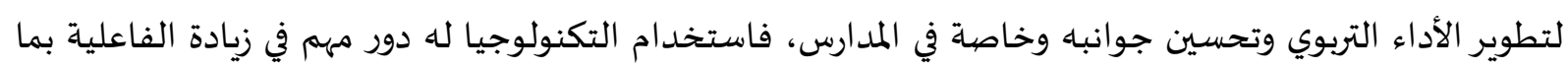

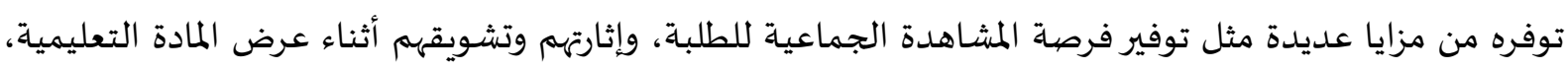
وتسمح لهم بالتفاعل الحركي مع التقنية بشكل مفيد وممتع، كما تساهم هذه التكنولوجيا بتوفير بيئة متفاعلة

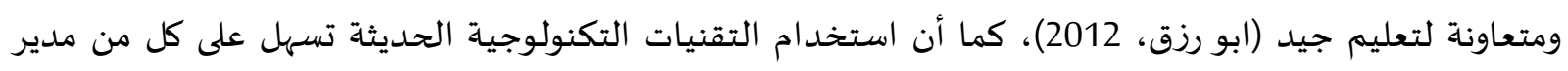

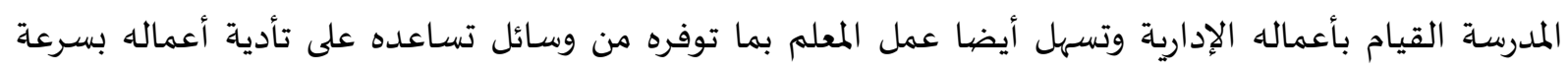

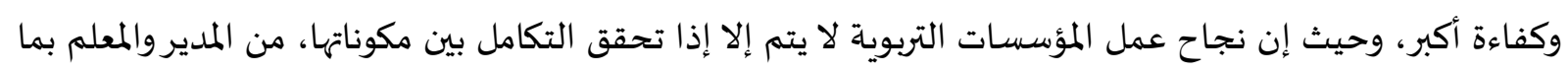

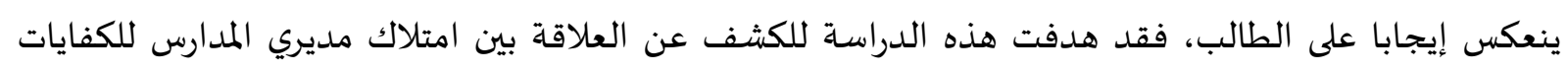
التكنولوجية ودرجة توظيف المعلمين لها، وتتحدد مشكلة الدراسة بالتساؤلات الآتية:

أسئلة الدراسة

تتحدد مشكلة الدراسة في الأسئلة الآتية:

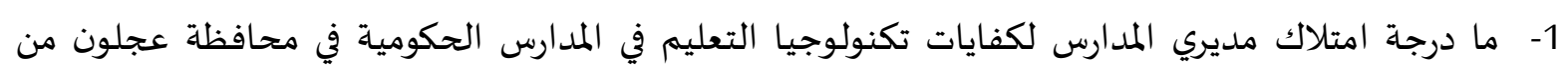

وجهة نظر المعلمين؟ ماك درجه

2- ما مستوى توظيف معلمي المدارس الحكومية في محافظة عجلون لتكنولوجيا التعليم من وجهة نظرهم؟

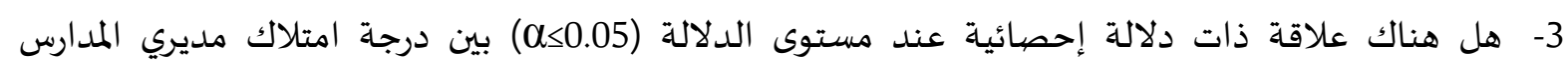

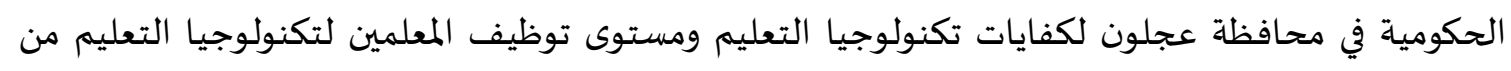

وجهة نظر المعلمين؟

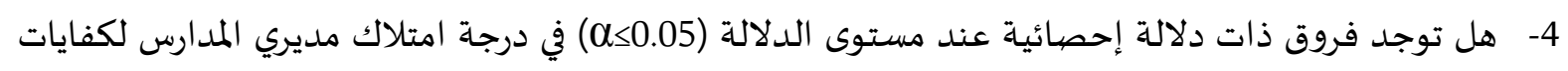
تكنولوجيا التعليم من وجهة نظر المعلمين تعزى لمتغير (الجنس، المؤهل العلمي) دلا؟ 


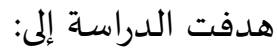

1- تعرف درجة امتلاك مديري المدارس لكفايات تكنولوجيا التعليم في المدارس الحكومية في محافظة عجلون من وجهاة نظر المعلمين.

2- تعرف درجة توظيف معلمي المدارس الحكومية في محافظة عجلون لتكنولوجيا التعليم من وجهة نظرهم. 3- الكشف عن العلاقة بين درجة امتلاك مديري المدارس الحكومية في محافظة عجلون لكفايات تكنولوجيا التعليم ودرجة توظيف المعلمين لتكنولوجيا التعليم من وجهة نظر المعلمين. 4- تعرف أثر متغيري الدراسة (الجنس، المؤهل العلمي) في درجة امتلاك مديري المدارس لكفايات تكنولوجيا التعليم من وجهة نظر المعلمين.

أهمية الدراسـة

تكمن أهمية الدراسة من أهمية الموضوع الذي تناولته، وهو كفايات تكنولوجيا التعليم، كما وتنبع أهمية

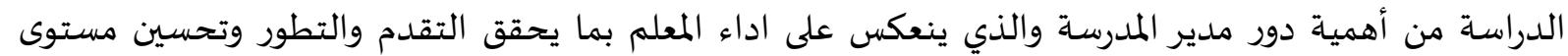
الطلبة؛ وعليه فإن للدراسة الحالية أهميتان (نظرية، وعمليه):

\section{الأهمية النظرية:}

من المؤمل أن تضيف الدراسة الحالية للأدب النظري بما يفيد الباحثين في مجالي الإدارة التربوية

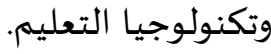

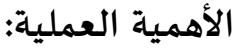

يؤمل من الدراسة الحالية أن تفيد: - مديري المدارس بأن تزيد من وعيهم بأهمية تكنولوجيا التعليم في العملية التعليمية، وستسهم نتائج الدراسـة في

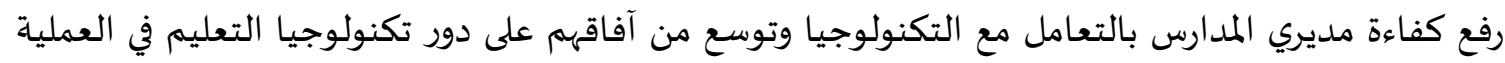
التعليمية وأثرها في رفع التحصيل لدي الدي الطلبة.

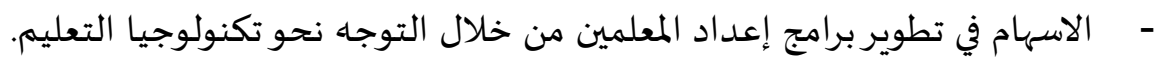
- تطوير دورات تدريب المعلمين في أثناء الخدمة على أساس الكفايات التكنولوجية والاحتياجات الفعلية.

حدود الدراسة الحد الموضوعي: العلاقة بين درجة امتلاك مديري المدارس لكفايات تكنولوجيا التعليم ومستوى توظيف المعلمين لتكنولوجيا التعليم. الحد البشري: معلمي ومعلمات المدارس الحكومية في مديرية تربية عجلون.

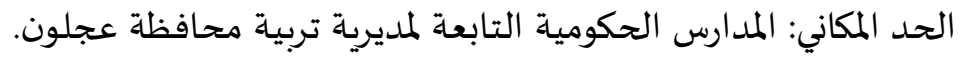
الحد الزماني: الفصل الدراسي الثاني من العام الدراسي 2021/2020.

$$
\text { مصطلحات الدراسة }
$$

- تكنولوجيا التعليم: "هي عملية الإفادة من المعرفة العلمية وطرائق البحث العلهي في تخطيط وحدات النظام التربوي وتنفيذها وتقويمها كل على انفراد وككل متكامل بعلاقاته المتشابكة بغرض تحقق سلوك معين في المتعلم

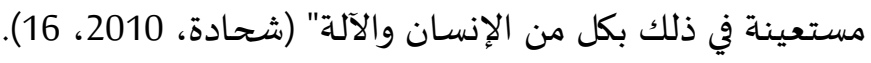


- الكفاية: هي "القدرة المتكاملة التي تمكن الفرد من اداء مهارات وسلوكيات معينة مرتبطة بما يقوم به من مهام

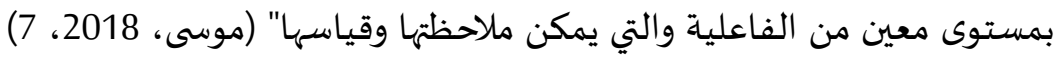

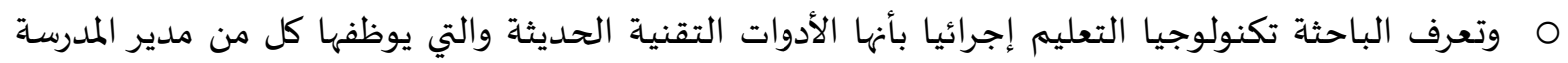

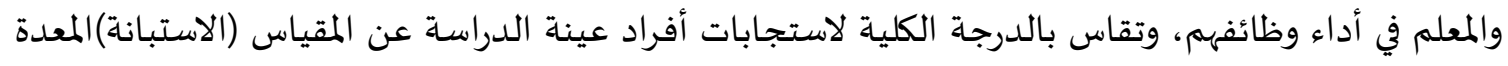
لهذا الغرض. O كفايات تكنولوجيا التعليم للمدير إجرائيا: المهارات التكنولوجية التي يمتلكها مديري المدارس في مجال عملهم الإداري وقدرتهم على استخدامها، وتقاس بالدرجة الكلية لاستجابات أفراد عينة الدراسة على الأداة المعدة

- مدير المدرسة: " هو وصف وظيفي لإدارة المدرسة فنيًا وإداريًا بما يحقق رسالة المدرسة التربوية وفقًا للمناهج والسياسات التربوية، بما يخدم العملية التعليمية التعلمياة، في ضوء الموارد والإمكانات المتاحة" (وزارة التربية المادية

والتعليم، 2014).

2- - الإطار النظري والدراسـات السـابقة. أولاً - الإطار النظري. مفهوم تكنولوجيا التعليم: ظهر مفهوم تكنولوجيا التعليم باعتباره عملية متكاملة تقوم على تطبيق هيكل من العلوم والمعرفة

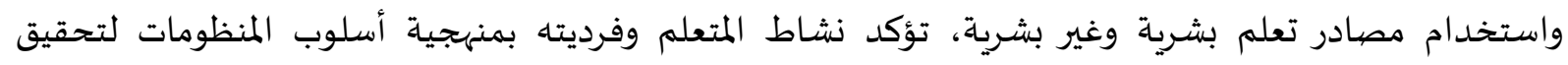

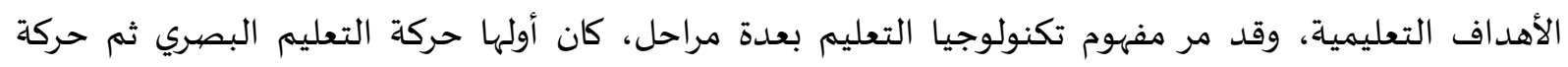

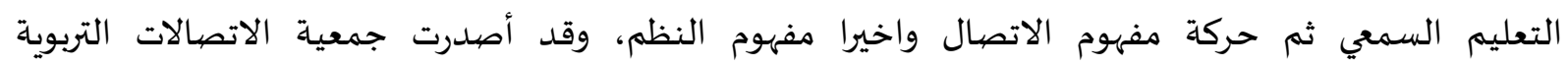

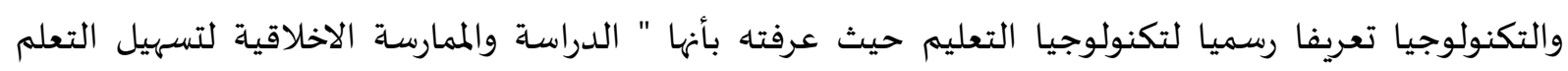

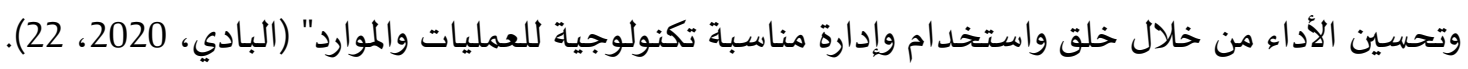

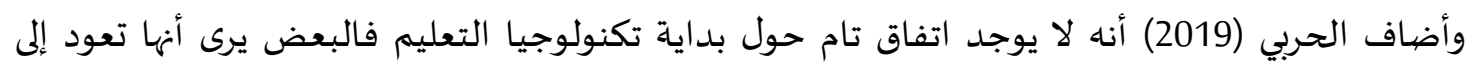

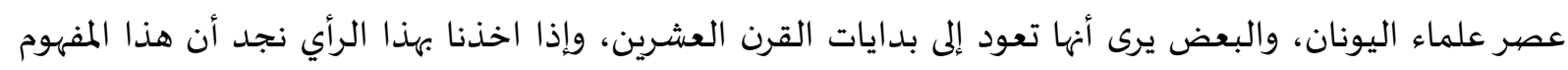

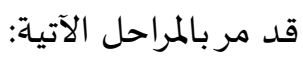
- التعليم البصري : هو أي وسيلة أو طريقة تعتمد على النظر في تقديم عرض المعلومات، وتطورت هذه الوسائل عن طريق اكتشاف الأصهوات والأفلام المُتحركة الناطقة.

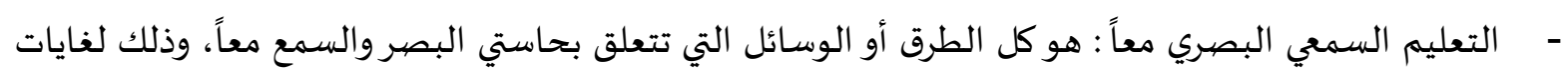
نقل الأفكاروالمعلومات والخبرات للمتلقي بالشكل المناسب.

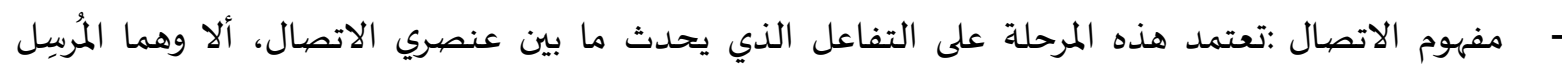

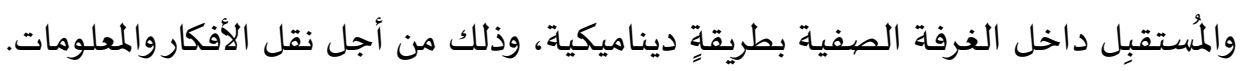

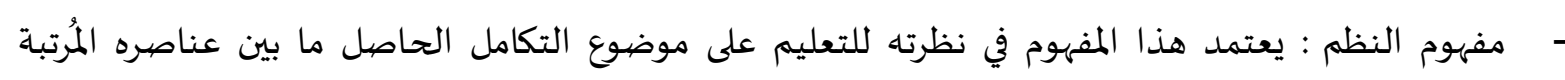
والمنظمة، حيث تعمل معاً لتحقيق الأهداف المشتركة والمرجوة. 
- العلوم السُّلوكية :كانت هذه المرحلةُ تعتمد على سلوك الفرد المُتعِلم، والظُروف والبيئة التي يحدث فيها التعلم، فهي تُؤثر بشكلٍ رئيسي في سير عملية التعليم، ولكن يُضاف إلى ذلك مراعاة استخدام الأدوات المساعِدة التي

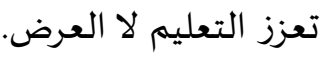

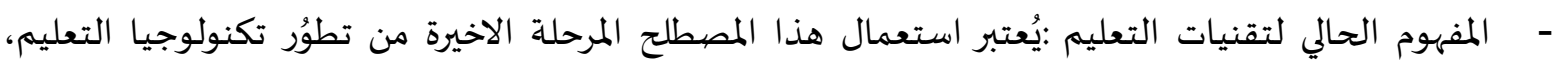

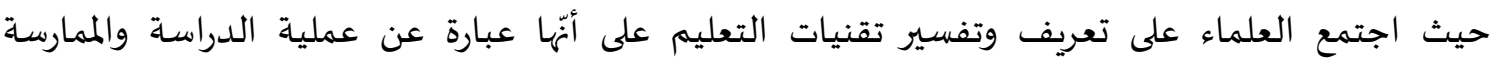
الاخلاقية التي تُسير التعلم، وتحسن الأداء (التعليم والتعلم) عن طريق إنشاء تعنيات واستخدام وإدارة العمليات والموارد التقنية الملائمة في التعلم.

أهمية تكنولوجيا التعليم:

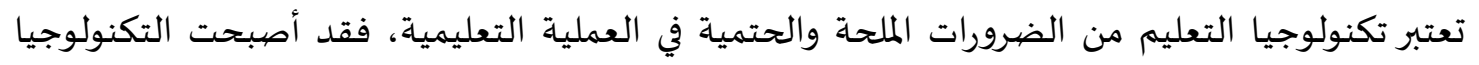

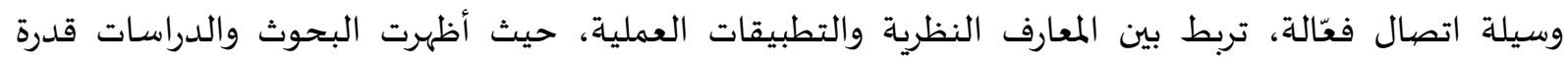

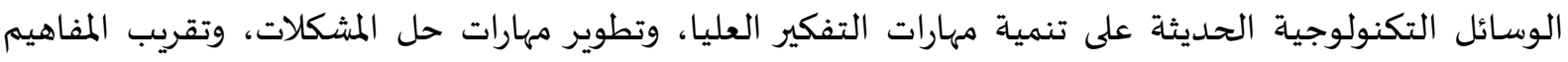

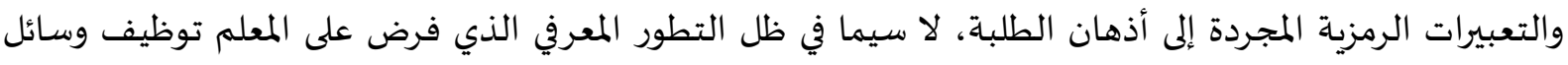

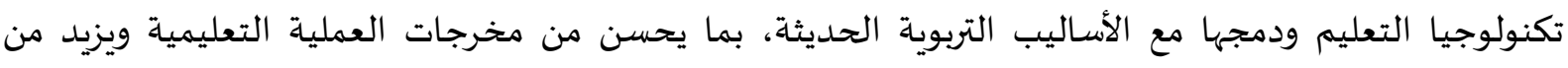

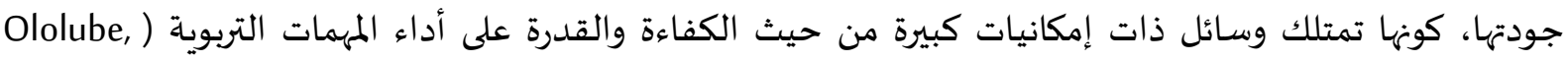

.)(2006

وتكمن اهمية تكنولوجيا التعليم في المساعدة على استثارة اهتمام المتعلم وإشباع حاجته للتعلم وتكوين اتجاهاتهم الجديدة للتعلم واكتسابهم الخبرة وزيادة المشاركة الفاعلة للمتعلم مما يجعله أكثر استعداداً، كما أهنا

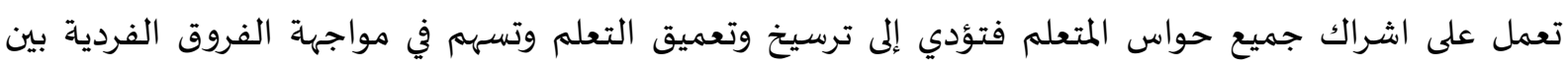

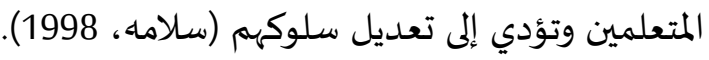
وأشار العزاوي وعبود في المؤتمر العلمي الأول إلى أن تكنولوجيا التعليم تتبلور أهميتها في توفيرها الوقت المتادي

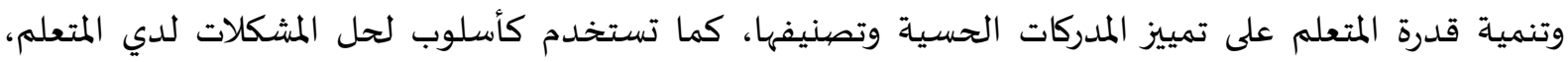

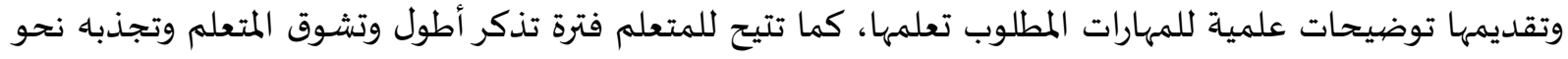
الدرس وتنمي الميول الإيجابية لدياه وتقوي شخصيته وتنمي التفكير الإبداعي لديه (العزاوي وعبود، 2008).

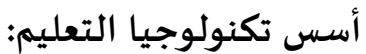

تؤدي تكنولوجيا التعليم دورا هاما في تطوير عملية التعلم والتعليم، وتساعد في حل المشكلات التي تواجهاه،

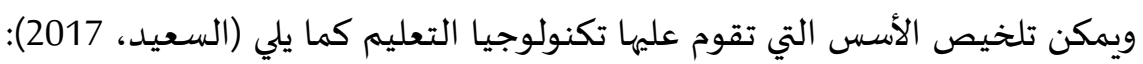

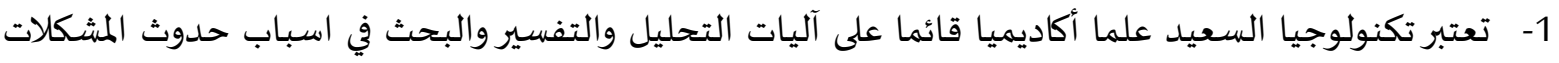

$$
\text { التعليمية والعوامل المؤثرة فيهان والبحث عن الحلول المناسبة لهيا لهاديا. }
$$

2- تقوم تكنولوجيا التعليم على منطق التفكير العلمي والمنهج التجريبي في حل المشكلات التعليمية كما أنها تعتمد على مدخل النظم في دراسة المؤثرات والمكونات في عمليتي التعليم والتعله. 3- تكنولوجيا التعليم علم يجمع النظري والتطبيقي، حيث يعتمد على جانب الممارسات والإجراءات التطبيقية

$$
\text { والاستفادة منها في دعم الجانب الأكاديمي. }
$$

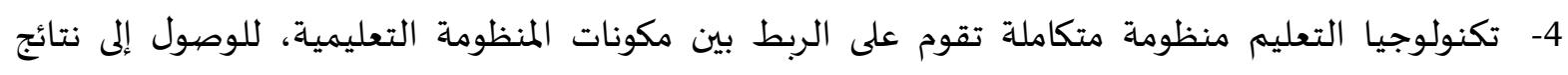

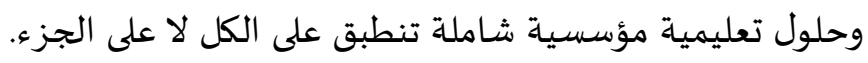


عناصر تكنولوجيا التعليم:

عرفت جمعية الاتصالات والتكنولوجيا الأمريكية (AECT) تكنولوجيا التعليم بأهها "الدراسة والممارسة الاخلاقية الخاصة بتسهيل التعلم وتحسين الأداء من خلال ابتكار العمليات والمصادر التكنولوجية المناسبة

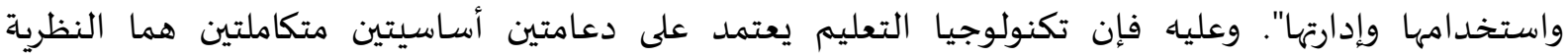

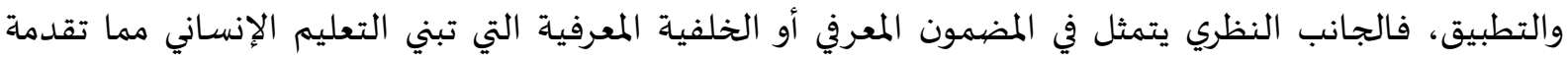
العلوم المختلفة، والجانب التطبيقي نستفيد منه من خلال عمليات أساسية، مثل تصميم مصادر التعلم المختلفة، إنتاجها وتقويمها واستخدامها، والرابط بين الجانبين هو الصلة الوثيقة بين العمليات، فلا تستقيم عملية التصميم إلا من خلال جمع المعلومات وتحليلها، والانتاج والاستخدام (السعيد، 2017).

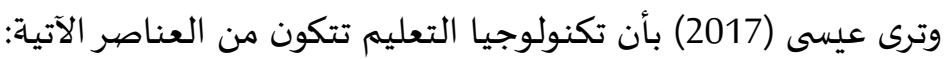

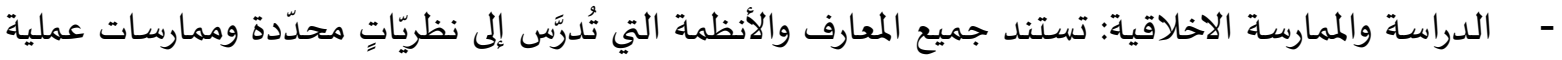

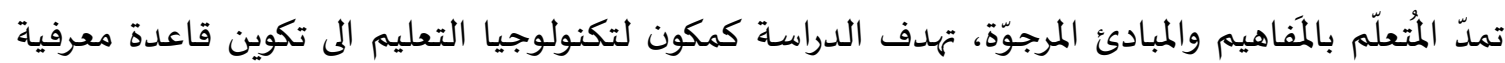
تكون موجهة للجانب التطبيقي للتكنولوجيا.

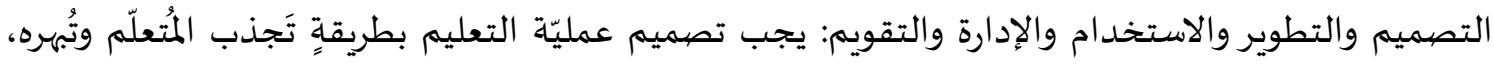

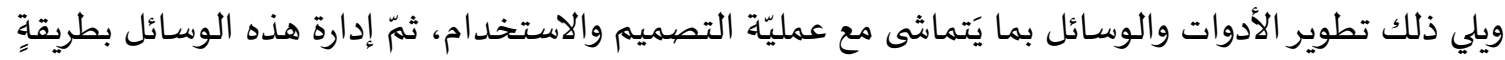
فعّالة، وتقويمها بما يَصلح للعملية التعليميّة. - العمليات والمصهادر: تشمل العمليّات سلسلة الإجراءات التي تُوجّها من أجل تحقيق هدفٍ مُحدّد، أمّا المصهادر فهي التسهيلات التي يتم تزويدها من أجل دعم عمليّة التعلم، وتتميز تكنولوجيا التعليم بتعدد مصادرها، وقد اتسعت لتشمل الابتكارات التكنولوجية والأدوات والتقنيات التي تسعى لمساعدة المتعلم على التعلم

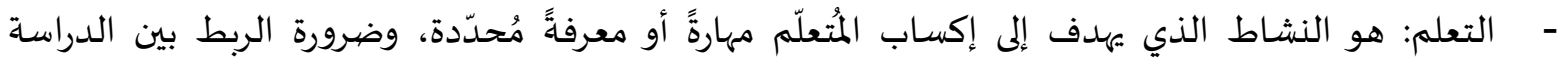
والممارسة، وتوظيف ما تعلمه الفرد في حياته خارج حدود المدرسة، وان التعلم تفاعل والمتعلم نشط والمعلم ـ ـ التعليم: هو التصميم والأسلوب المُنظم الذي يُسـاعد الشخص المتُعلّم على إنجاز التغيير الذي يَرغب به في بما أن المعلم هو جوهر العملية التعليمية فلا بد له من الانفتاح على التطورات في العملية التعليمية بما

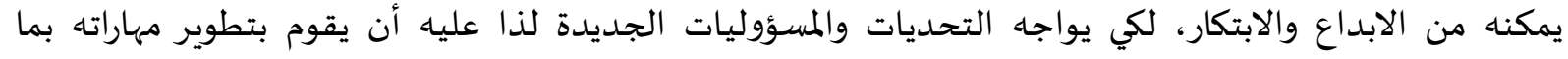

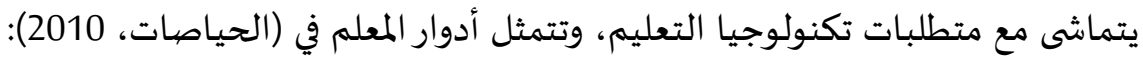

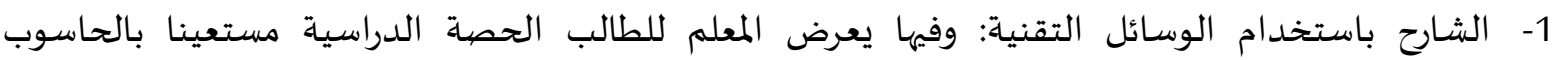

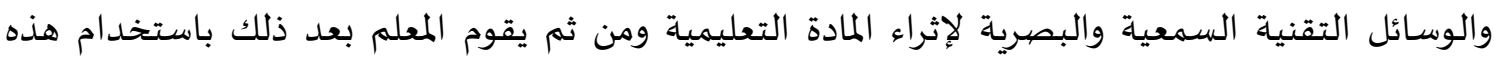
التكنولوجيا كمصادر للبحث والقيام بالمشاريع المكتبية، حيث يقوم المعلم بالشرح للطالب عن كيفية 
3- دور المشجع على توليد المعرفة والإبداع: وفيها يشجع المعلم الطالب على استخدام الوسائل التقنية وابتكار

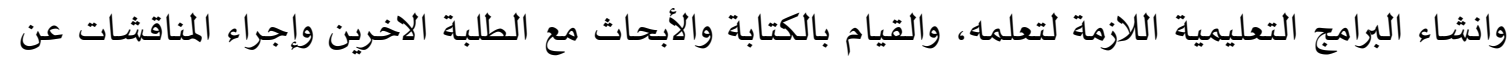
طريق البريد الإلكتروني. كفايات تكنولوجيا التعليم: لتكنولوجيا التعليم دور مهم في تحفيز المتعلمين وإثارة دافعيتهم لعملية التعليم وتركيز انتباههم في الموضوع

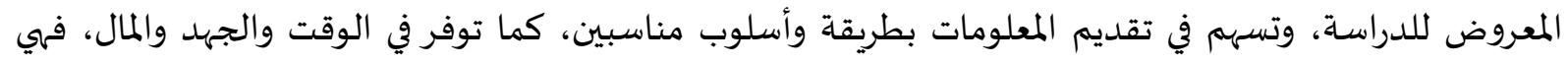

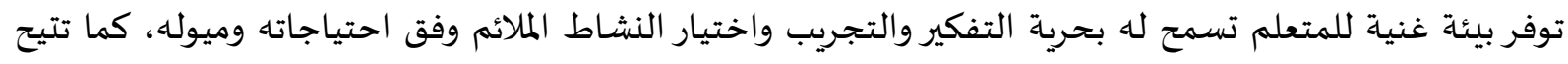
للمتعلم فرص المحاولة والتجريب (مرعي، 2005). كما أن توظيف الكفايات التكنولوجية في العملية التعليمية من قبل المعلمين يساعد في في تفعيل التعليم

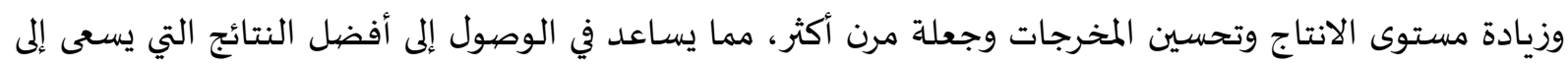
تحقيقها (الحسبان، 2014).

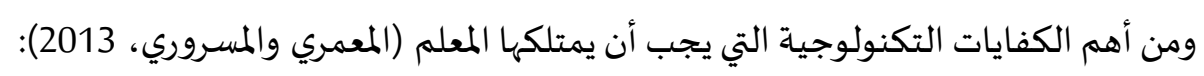

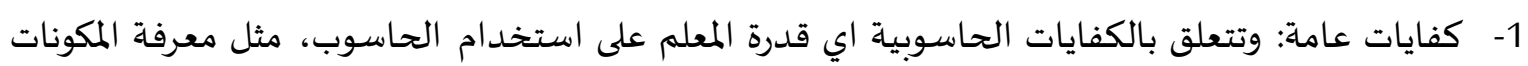

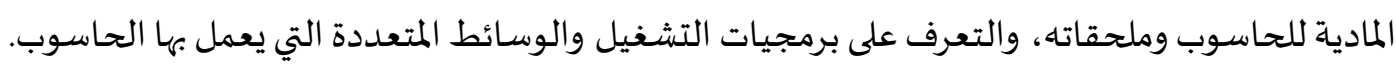

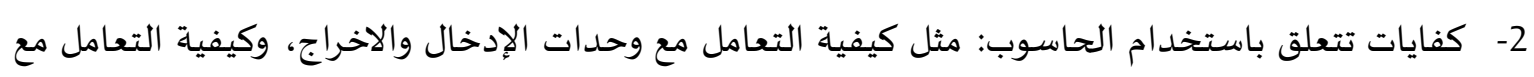
الملفات وطرق حفظها وتخزينها وغيرها. 3- كفايات تتعلق بالثقافة المعلوماتية: مثل استخدام شبكة الإنترنت في العملية التعليمية وذلك من خلال البحثث

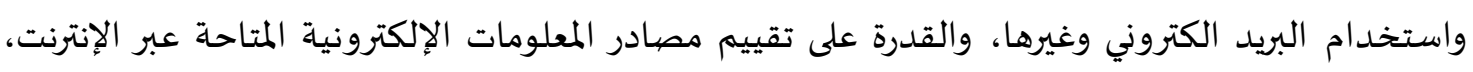

$$
\text { وتصميم الصفحات التعليمية. }
$$

4- كفايات التعامل مع برامج وخدمات شبكة الإنترنت: مثل إجادة اللغة الإنجليزية، والتعامل مع الخدمات

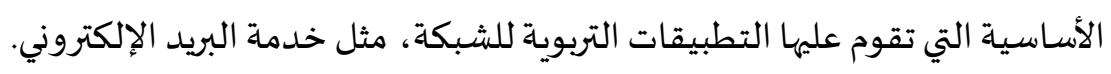

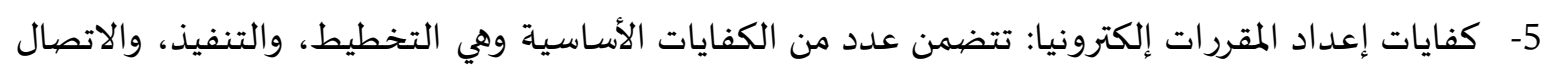

$$
\text { والتقييم. }
$$

دور مدير المدرسة في توظيف تكنولوجيا التعليم:

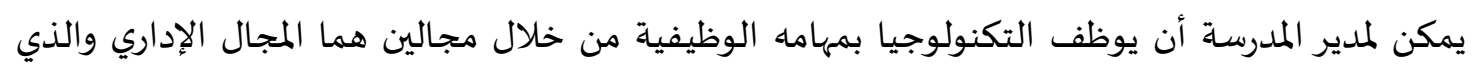

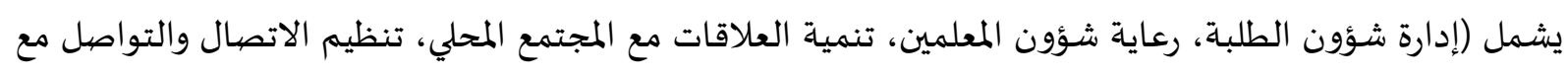

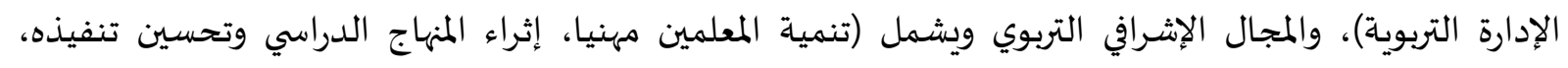

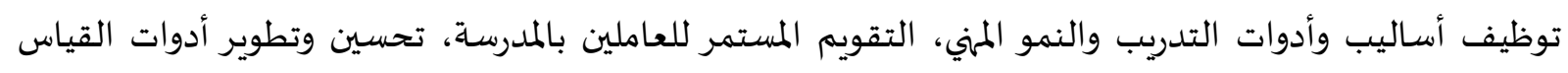

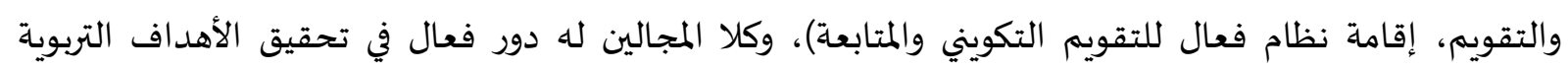
(العمايرة، 2015).

وأضاف (Baylor, Ritchie, 2002) أهمية دور مدير المدرسة في تسهيل إدخال تكنولوجيا المعلومات والاتصالات إلى مجتمع المدرسة، واتخاذ القرارات اللازمة، والتدخل في الوقت المافية المناسب في أثناء عملية التطبيق، ويستطيع المدير المتقن لاستخدام الوسائل التقنية الحديثة تسهيل عملية التفاعل بين المعلمين وتبادل الخبرات المبرات فيما 
بينهم، وإيجاد بيئة تعليمية للمعلمين، ومتابعة طرق استخدام التكنولوجيا المتوفرة في عملية التدريس من خلال التواصل مع المعلمين أو مع الإدارات العليا أو مع أولياء الأمور.

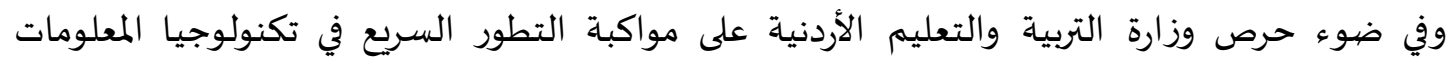

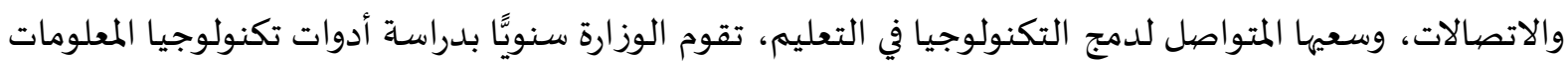

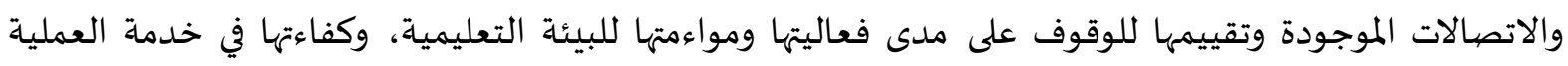

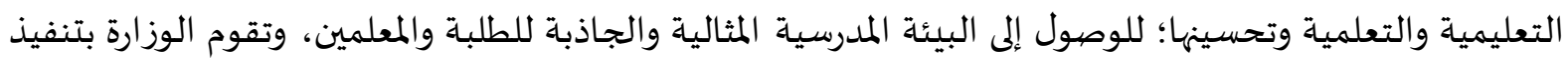
عدة مشاريع مختصبة لرفع كفاءة التكنولوجيا وقد قامت لجنة مختصاة من الخبراء والمستشارين من داخل الوزارة

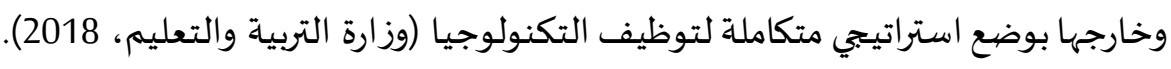

ثانياً- الدراسات السابقة: تعددت الدراسات التي تناولت موضوع تكنولوجيا التعليم، ومن بين الدراسات التي اهتمت بموضوع

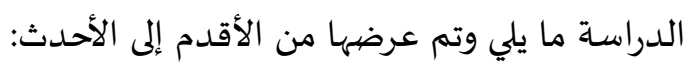
- - هدفت دراسة (Robert, 2011) إلى تحليل تصورات مديري المدارس حول الإست استخدام تكنولوجيا الإدارة الإلكترونية

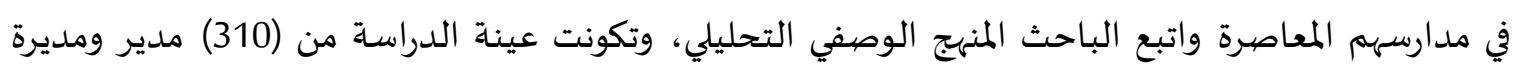

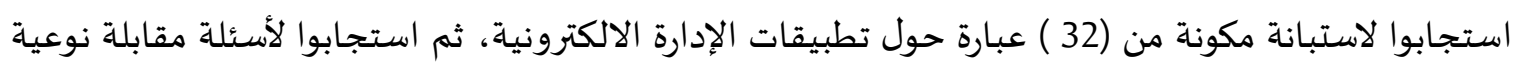

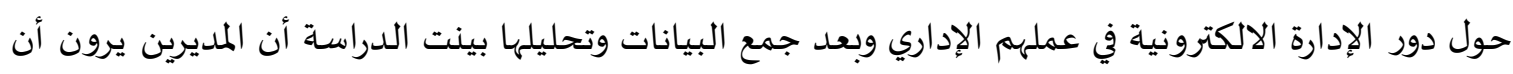

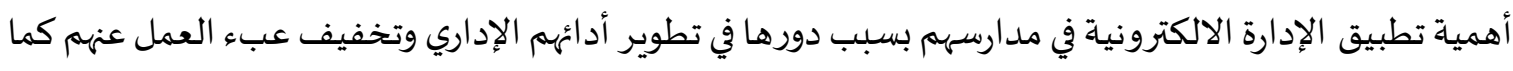

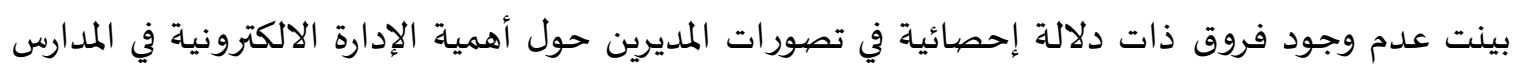

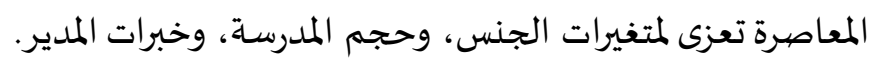

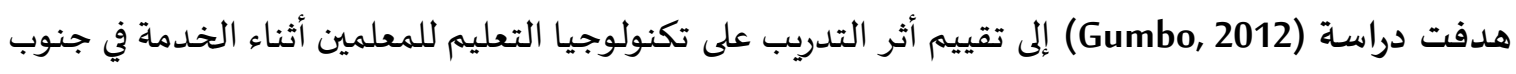

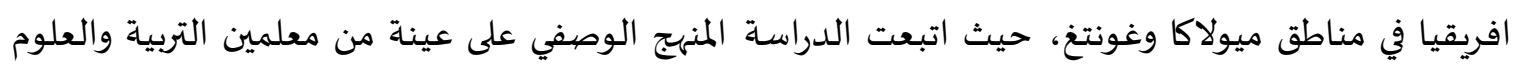

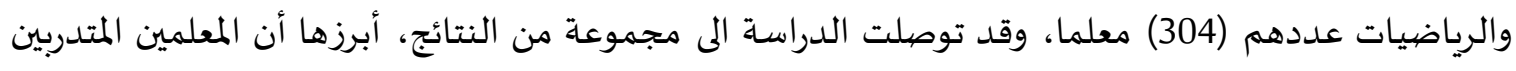

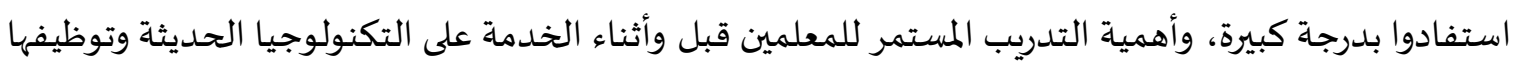
في التربية والتعليم. - هدفت دراسة حمادات (2016) التعرف على درجة استخدام المشرفين التربويين لتكنولوجيا المعلومات والاتصالات في برامج تدريب المعلمين في الأردن والصعوبات التي يواجهونها من وجهة نظر التهات المعلمين تكونت عينة

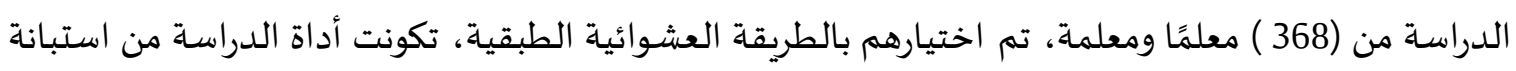

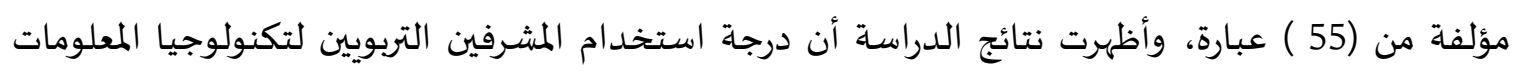

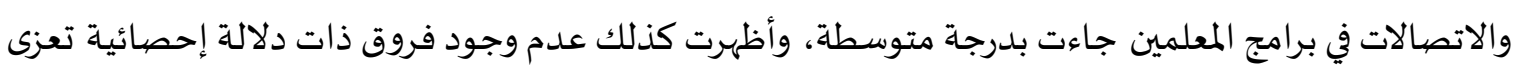

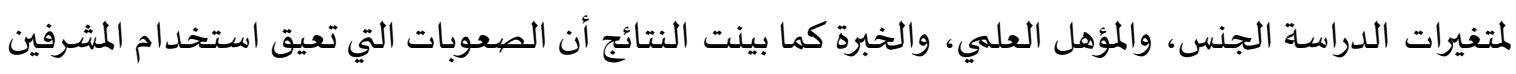

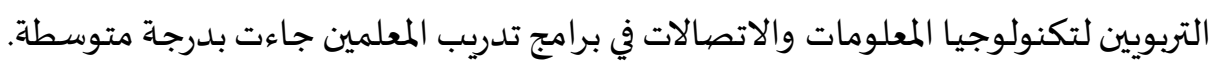

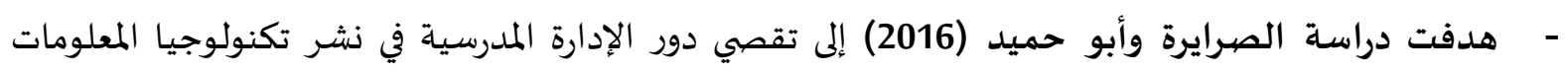

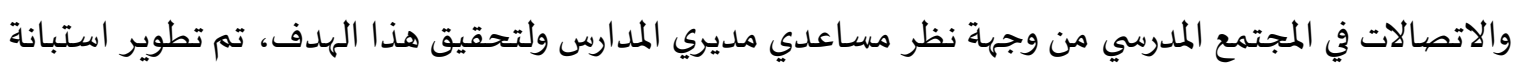

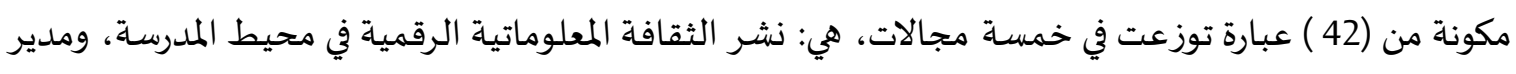

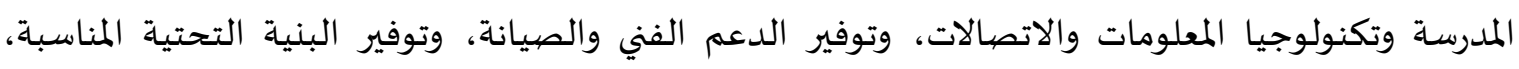


وتشجيع المعلمين على استخدام تكنولوجيا المعلومات والاتصالات، أما عينة الدراسة فتألفت من (74 ) من

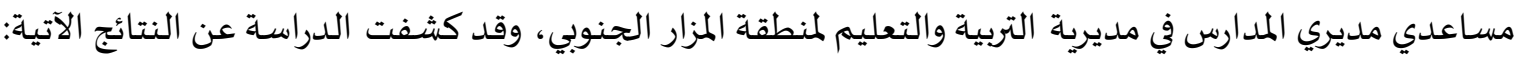

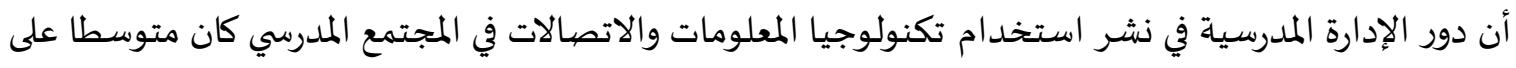

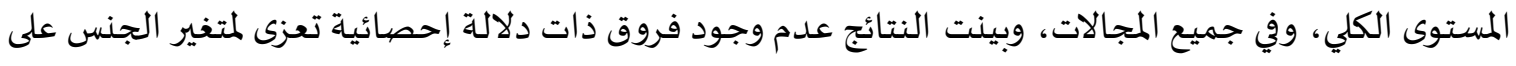

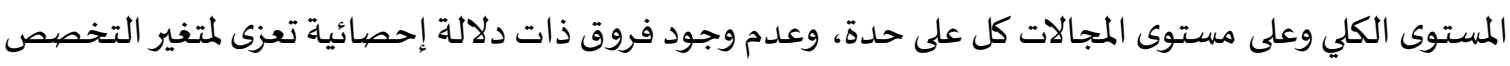

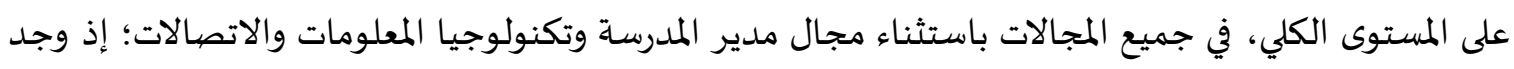
فياء فرق لصالح التخصصيات الإنسانية. وهدفت دراسة قرارة (2017) التعرف على دور تكنولوجيا التعليم في تطوير كفاءات المتعلمين في مرحلة التعليم

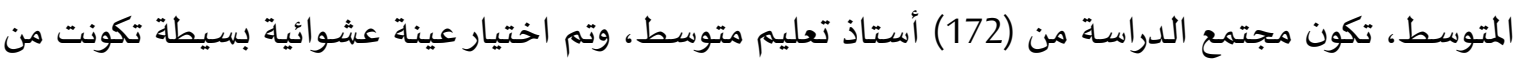

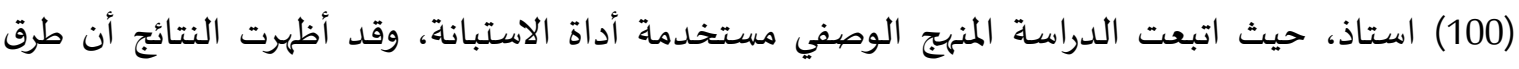

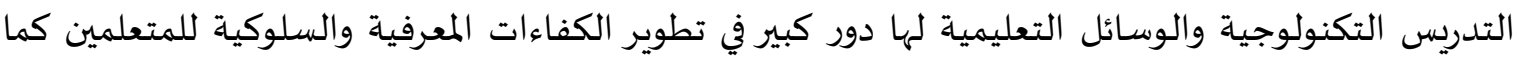
أظهرت أن التقويم التربوي بالأساليب التكنولوجية لا يطور الكفاءة الاجتماعية. هدفت دراسة (Ira et al, 2019) التعرف على آراء مديري المدارس الثانوية في توظيف التعلم الخلوي في مقاطعة

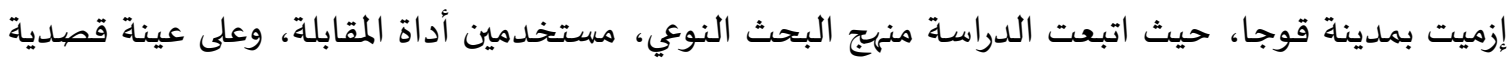

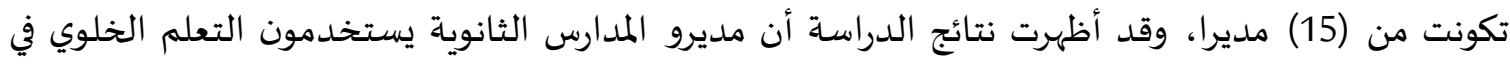

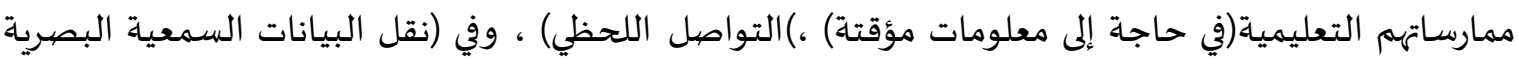

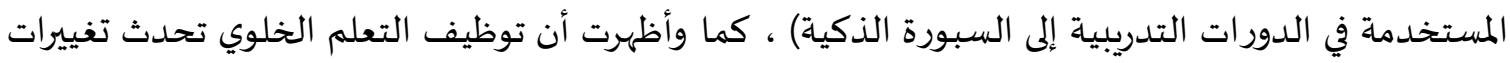

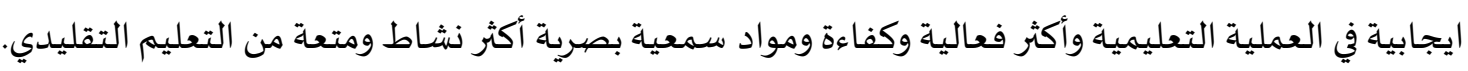
- هدفت دراسة عمايرة (2019) التعرف على درجة توافر الكفايات التكنولوجية لأعضاء هيئة التدريس في

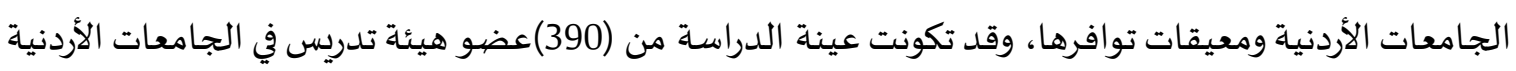

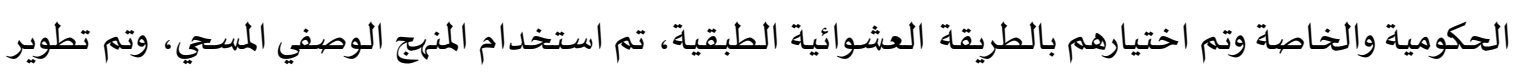

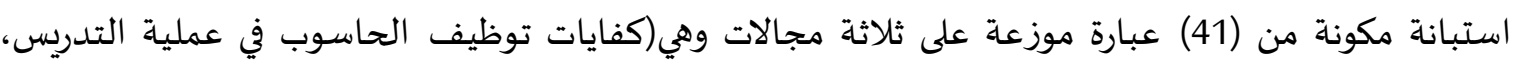

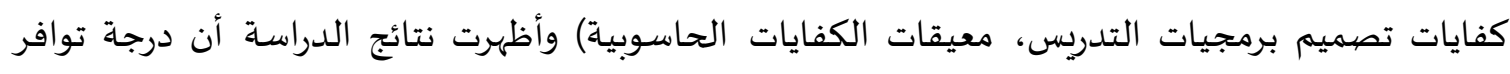

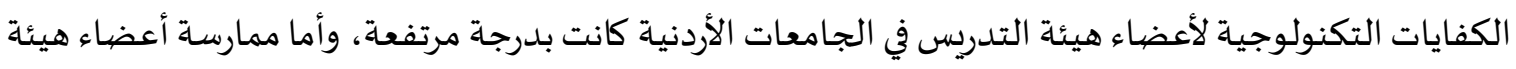

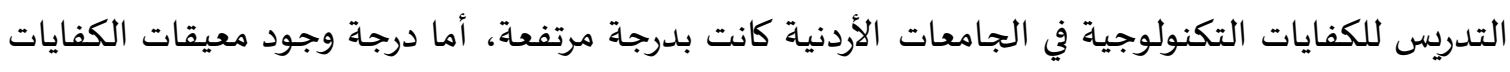

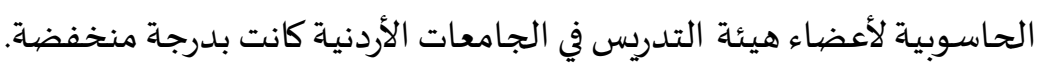

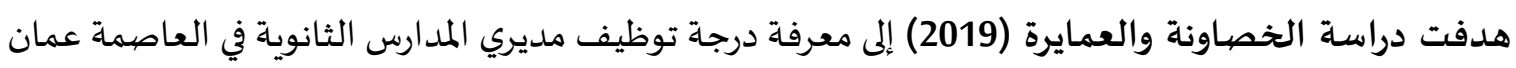

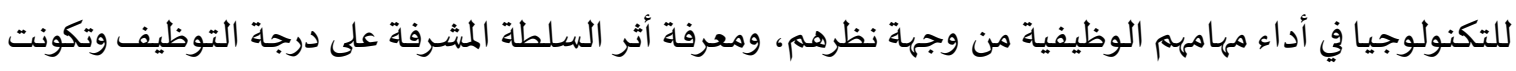

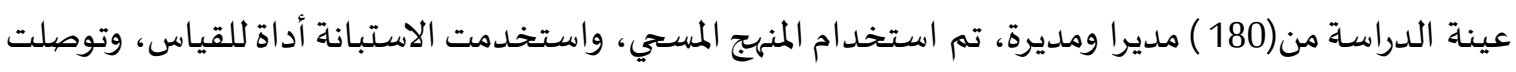

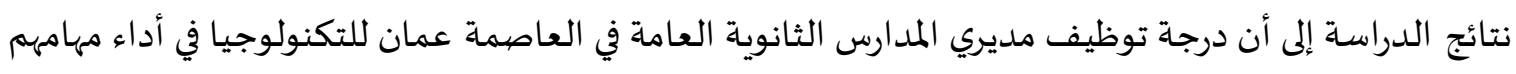

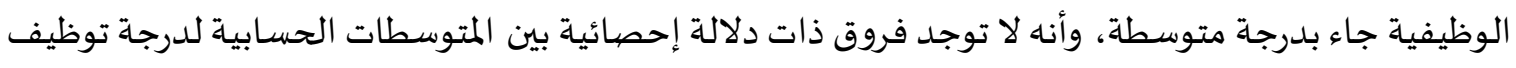

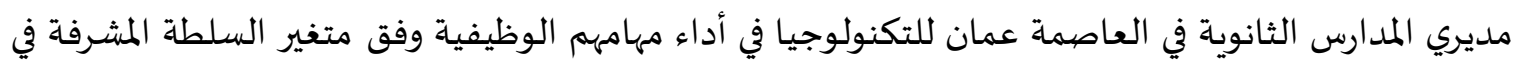

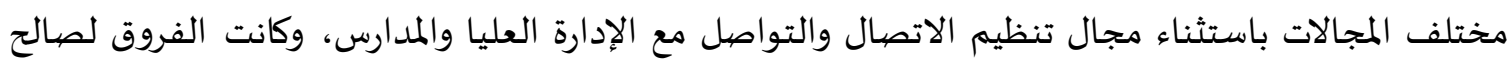
مديري القطاع العام. 
وهدفت دراسة البادي (2020) إلى التعرف على واقع توظيف تكنولوجيا التعليم في العملية التعليمية في مدارس

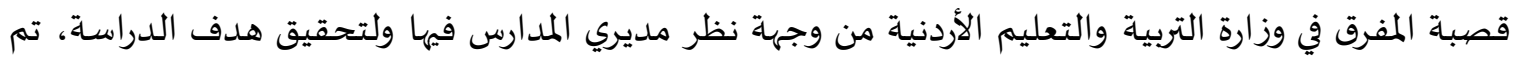

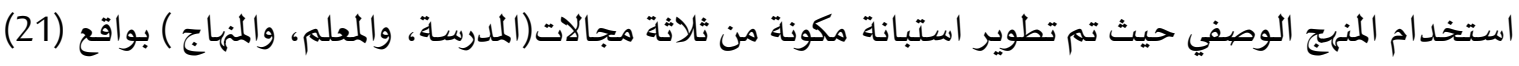

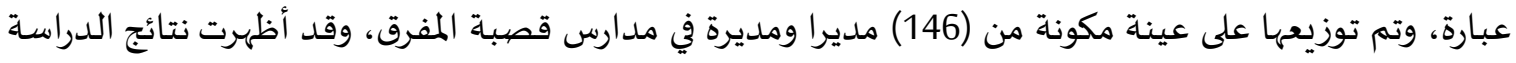

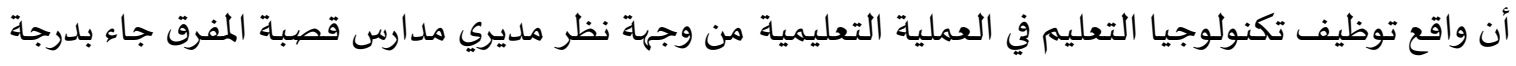

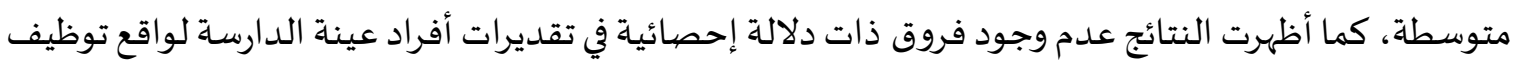

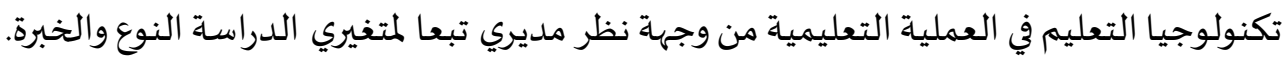
هدفت دراسة الشديفات والزبون (2020) التعرف على واقع توظيف تكنولوجيا التعليم في العملية التعليمية في مدارس قصبة المفرق من وجهة نظر المعلمين فيها ولتحقيق هدف الدراسة تن استخدام المنهج الوصفي حيث

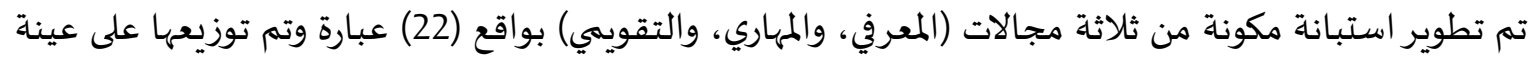

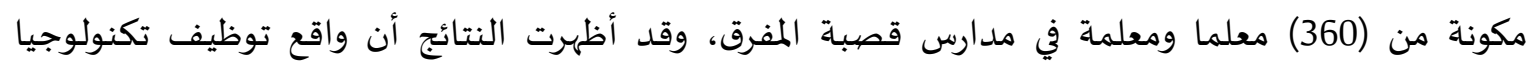

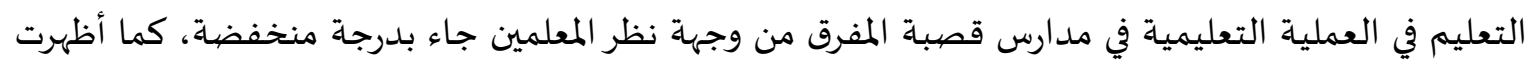

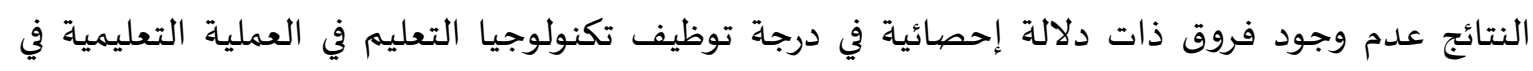

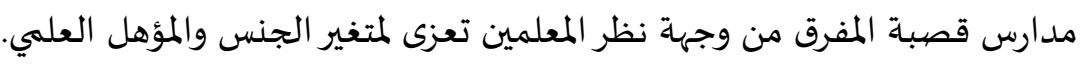

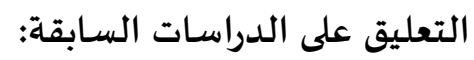

من خلال استعراض الدراسات السابقة العربية والأجنبية، قام الباحث ببيان أوجه الشبه والاختلاف بينن

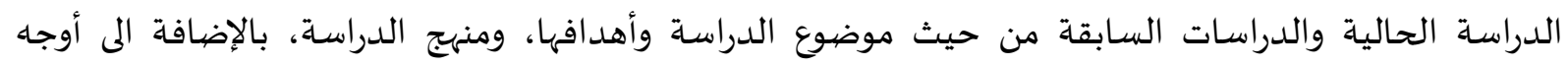
الاستفادة من الدراسات السابقة، وأبرز ما تتميز به الدراسة الحالية عن الدراسات الدات السابقة.

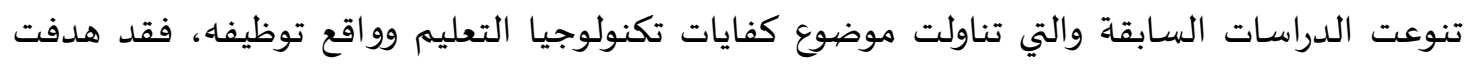
دراسة الشديفات والزبون (2020) ودراسة البادي (2020) التعرف على واقع توظيف تكنولوجيا التعليم في العملية

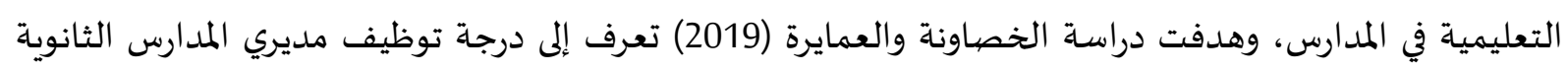

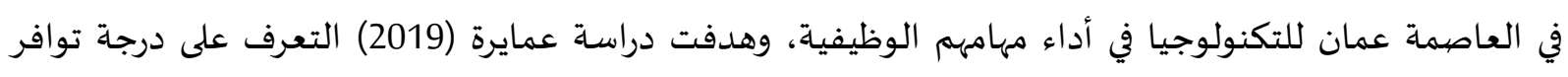

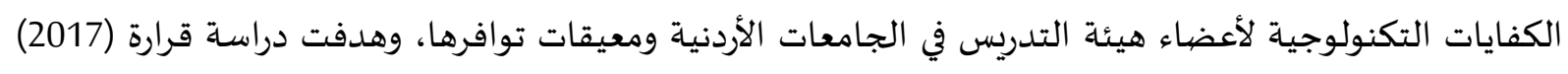

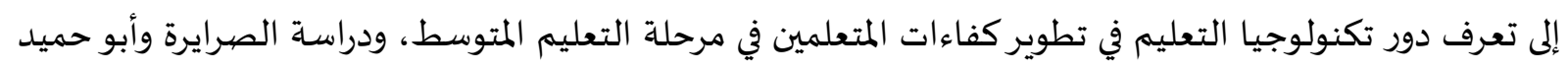

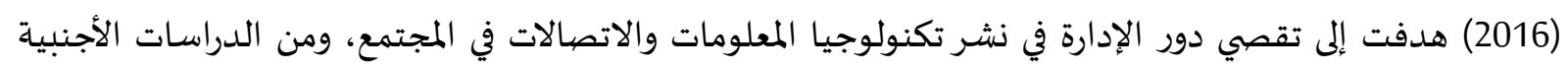

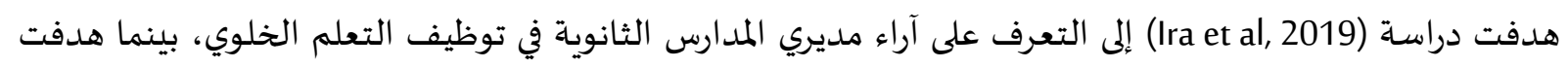

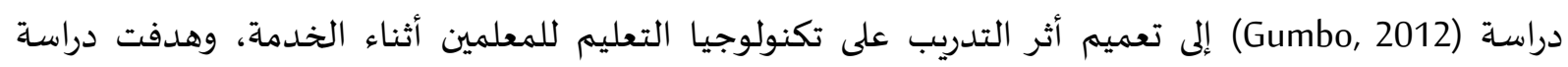
(Robert, 2011)

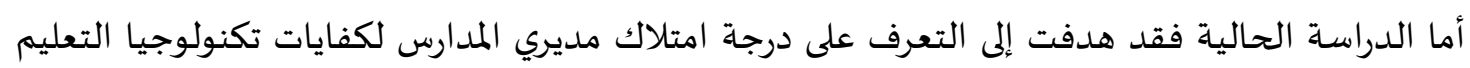
وعلاقته بمستوى توظيف المعلمين لتكنولوجيا التعليم من وجهة نظر المعلمين.

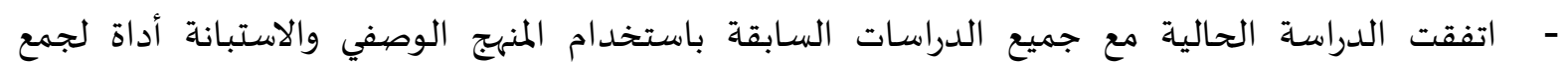
البيانات، بينما استخدم (Ira et al, 2019) المنهج النوعي والمقابلة لجمع البعات البيانات، ودراسة (Robert, 2011) اتبعت المنهج الوصفي التحليلي والمقابلة النوعية لجمع البيانات. - استفادت الدراسـة الحالية من الدراسـات السابقة في إعداد الإطار النظري وبناء عبارات الاستبانة. 
هدفت الدراسة الحالية للتعرف على درجة امتلاك مديري المدارس لكفايات تكنولوجيا التعليم وعلاقته بمستوى توظيف المعلمين لتكنولوجيا التعليم من وجهة نظر المعلمين، وتم اتباع المنهج الوصفي الارتباطي، ويعتمد

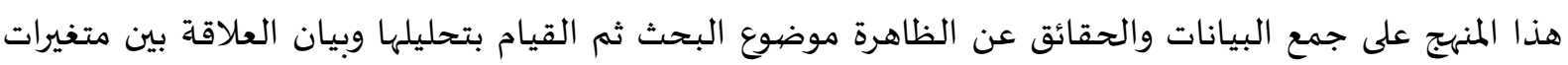

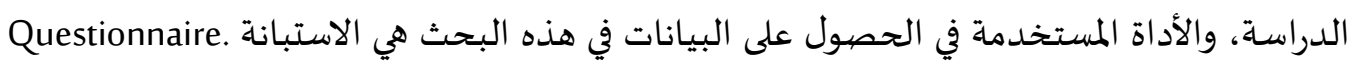

مجتمع الدراسة:

تكون مجتمع الدراسة من جميع معلمين ومعلمات المدارس الحكومية في محافظة عجلون في الفصل

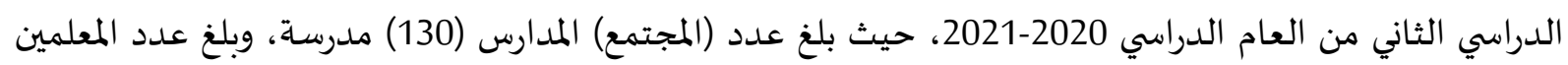

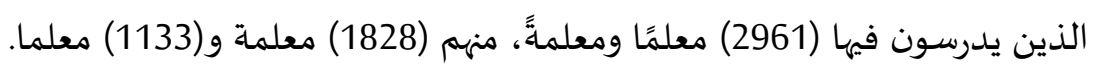

عينة الدراسـة: تم استخدام طريقتين لاختيار العينة هما الطريقة العنقودية العشوائية حيث تم اختيار عدد من مدارس

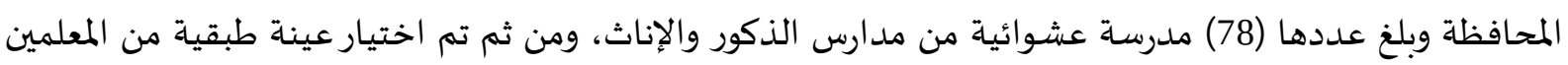

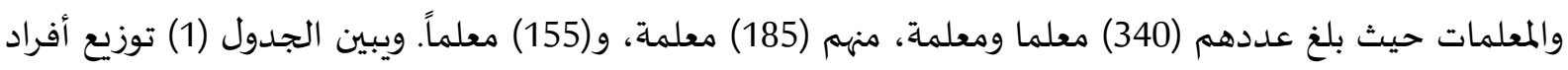

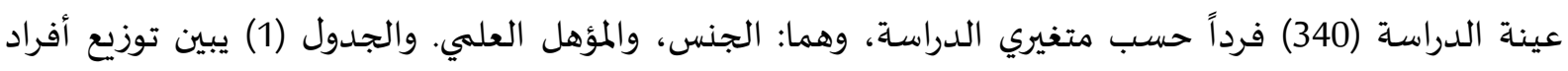
العينة تبعا لمتغيري الدراسة: الجنس والمؤهل العلمي. الجدول (1) توزيع أفراد العينة تبعا لمتغيري الدراسة: الجنسي المولس والمؤهل العلمي

\begin{tabular}{|c|c|c|c|}
\hline النسبة المئوية & التكرار & المستوى & المتغير \\
\hline 45.7 & 155 & معلم & \multirow{3}{*}{ الجنس } \\
\hline 54.3 & 185 & معلمة & \\
\hline 100.0 & 340 & المجموع & \\
\hline 59.8 & 175 & بكالوريوس & \multirow{3}{*}{ المؤهل العلمي } \\
\hline 40.2 & 165 & دراسات عليا & \\
\hline 100.0 & 340 & المجموع & \\
\hline
\end{tabular}

أداة الدراسةة:

لتحقيق أهداف الدراسـة تم إعداد استبانتين من قبل الباحثة وذلك بعد الرجوع للعديد من الدراسات ذات الصلة بموضوع الدراسة مثل دراسة خصاونة وعمايرة (2019) ودراسة البادي (2020) ودراسة الصرايرة وأبوحميد (2016) حيث تكونت الاستبانة الاولى من (20) عبارة وهدفت إلى تعرف درجة امتلاك مداسك مديري المدارس لكفايات

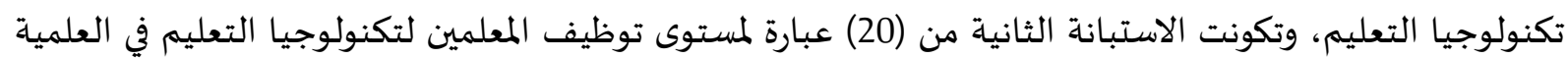




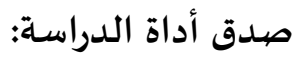

تم عرض الأداة على (5) محكمين من ذوي الخبرة والاختصاص؛ لمعرفة آرائهم حول عبارات الاستبانة، وفي

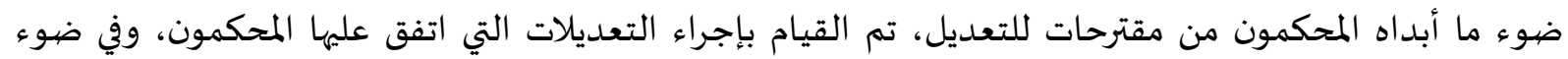

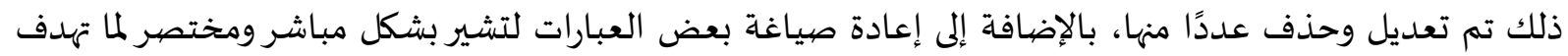
له العبارة، مما حقق الصدق الظاهري.

ثبات أداة الدراسـة: للتأكد من ثبات أداتي الدراسة، استخدمت الباحثة طريقة الاختبار وإعادة الاختبار (test-retest) حيث قامت الباحثة بتطبيق الأداة على عينة استطلاعية من خارج عينة الدراسة، وتكونت من (30) معلما ومعلمة وبفاصليل

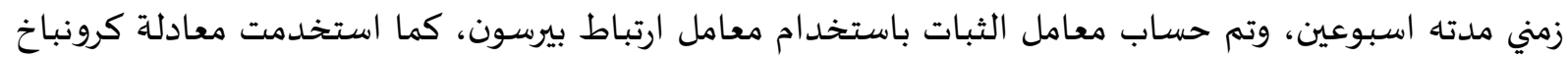
ألفا (Cronbach Alpha) والجدول (2) يبين ذلك:

جدول (2): معاملات ثبات أداتي الدراسة

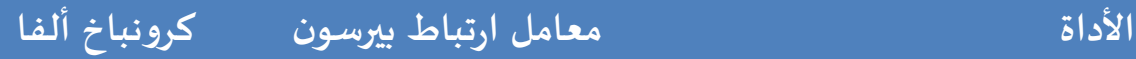

درجة امتلاك مديري المدارس لكفايات تكنولوجيا التعليم

0.92

0.89

مستوى توظيف المعلمين لتكنولوجيا التعليم

للإجابة استخدمت الباحثة مقياس ليكرت الخماسي بدءا من (درجة كبيرة جدا، درجة كبيرة، درجة متوسطة، درجة قليلة، درجة قليلة جدا) وتم إعطاؤها الأوزان الآتية مقابل كل تدريج (1,2,3,4,5) وتم اعتماد ادئه (تعديل) المقياس لتحديد مستوى الممارسة: (منخفض، متوسط، مرتفع) لدى أفراد عينة الدراسة، وهو: من من (1.00-

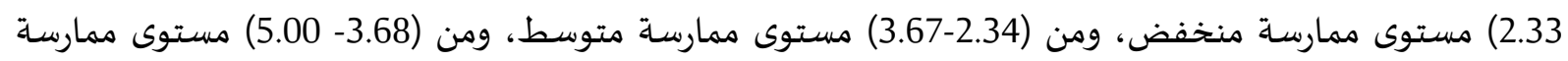

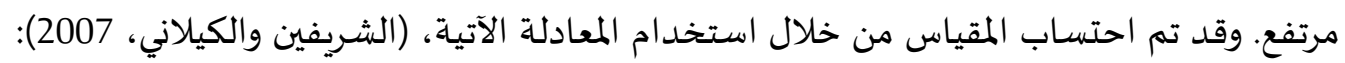

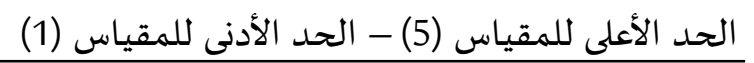

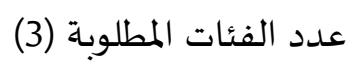

(طول الفئة) 1.33 = (1-5)

ومن ثم إضافة الجواب (1.33) إلى نهاية كل فئَة.

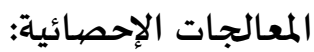

1- استخراج المتوسطات الحسابية والانحرافات المعيارية، لإجابات عينة الدراسة وذلك للإجابة عن السؤال الأول والسؤال الثاني.

2- كما تم استخدام معامل كرونباخ ألفا للتعرف إلى درجة ثبات الاستبانتين.

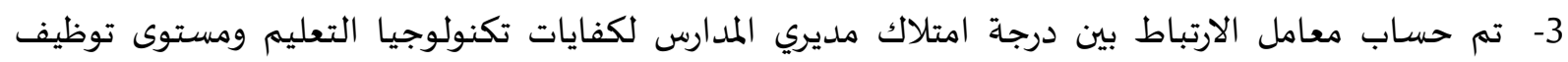
المعلمين لتكنولوجيا التعليم باستخدام معامل ارتباط بيرسون. 4- ولمعرفة أثر متغيري الجنس والمؤهل العلمي تم استخدام اختبار (T-Test) لعينتين مسستقلتين. 
4- عرض النتائج ومناقشتها. • الإجابة عن السؤال الأول: " ما درجة امتلاك مديري المدارس لكفايات تكنولوجيا التعليم في المدارس الحكومية في محافظة عجلون من وجهة نظر المعلمين"؟ ولإجابة عن السؤال تم استخراج المتوسطات الحسابية والانحرافات المعيارية لإجابات أفراد عينة الدراسة والجدول (3) يوضح ذلك.

الجدول (3): المتوسطات الحسابية والانحرافات المعيارية لدرجة امتلاك مديري المدارس لكفايات تكنولوجيا التعليم من وجهة نظر المعلمين مرتبة تنازليا

\begin{tabular}{|c|c|c|c|c|c|}
\hline التطبيق & الرتبة & 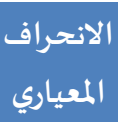 & المستوسط & 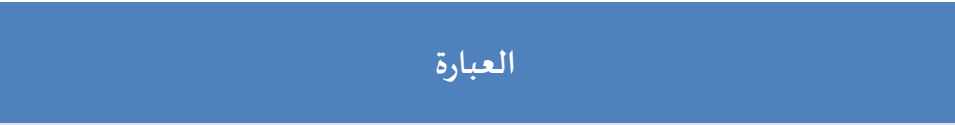 & r \\
\hline 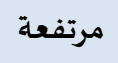 & 1 & 0.92 & 4.23 & يستخدم جهازعرض البيانات خلال الاجتماعات & 4 \\
\hline 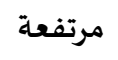 & 2 & 1.01 & 4.20 & يستخدم الانترنت في الاتصبال مع أولياء الأمور & 5 \\
\hline 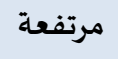 & 3 & 1.12 & 4.20 & يتصل إلكترونيا مع المديرين الاخرين في ما يخص تحسين الأداء & 2 \\
\hline 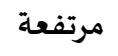 & 4 & 1.07 & 4.15 & يركز على ضرورة استخدام التكنولوجيا في تنفيذ الأنشطة المدرسية & 8 \\
\hline 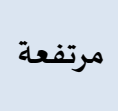 & 5 & 1.09 & 4.12 & يقوم بعقد دورات تدريبية للمعلمين على توظيف التكنولوجيا في المواد & 7 \\
\hline 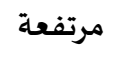 & 6 & 0.87 & 4.11 & يوظف التكنولوجيا في التخطيط الاستراتيجي للمدرسة & 1 \\
\hline 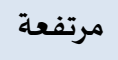 & 7 & 1.00 & 4.05 & يتابع السجلات الخاصة بالطلبة من حيث القبول والغياب إلكترونيا & 3 \\
\hline 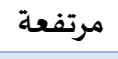 & 8 & 0.98 & 4.01 & يتابع اخر التطورات في مجال تكنولوجيا التعليم & 6 \\
\hline 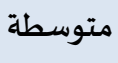 & 9 & 0.49 & 3.66 & ينظم جدول الحصص المدرسية باستخدام تكنولوجيا التعليم & 9 \\
\hline 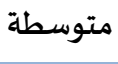 & 10 & 0.99 & 3.64 & يعمل على تطوير نفسه في مجال تكنولوجيا التعليم & 16 \\
\hline 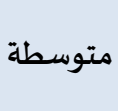 & 11 & 0.90 & 3.60 & يقسم الأعمال التكنولوجية بين المعلمين حسب تخصص كل معلم لرفع كفاءة & 14 \\
\hline متوسطة & 12 & 0.79 & 3.59 & يتابع التزام المعلمين باستخدام تكنولوجيا التعليم في الحصة الدراسية & 15 \\
\hline 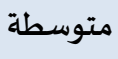 & 13 & 0.75 & 3.40 & ييئ الفرصة أمام المعلمين للكشف عن المبدعين في مجال تكنولوجيا التعليم & 11 \\
\hline 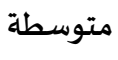 & 14 & 0.76 & 3.35 & يتابع فعاليات اليوم الدراسي باستخدام تكنولوجيا التعليم & 13 \\
\hline 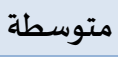 & 15 & 1.26 & 3.29 & يوفر حاجات المدرسة من الأدوات التكنولوجية الضرورية & 12 \\
\hline 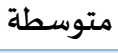 & 16 & 1.22 & 3.19 & يوثق بعض الحصص الصفية إلكترونيا & 10 \\
\hline 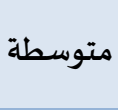 & 17 & 1.41 & 3.11 & يسعى إلى الاستفادة من خبرات أعضاء المجتمع المحلي في مجال تكنولوجيا & 20 \\
\hline 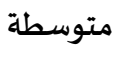 & 18 & 1.01 & 3.08 & يستثمر خبرات المعلمين في مجال تكنولوجيا التعليم ويوظفها & 17 \\
\hline 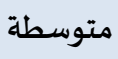 & 19 & 0.98 & 2.88 & يوظف التكنولوجيا في التخطيط بهدف تطوير التعليم. & 19 \\
\hline
\end{tabular}




\begin{tabular}{|c|c|c|c|c|c|}
\hline دالتطبيق & 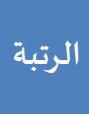 & 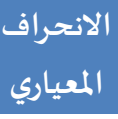 & المتوسط & 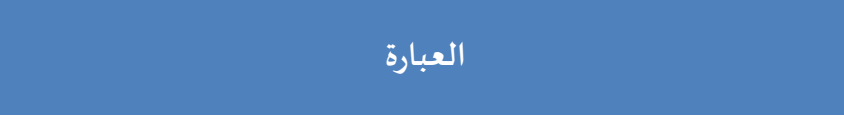 & $\hat{\imath}$ \\
\hline 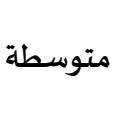 & 20 & 0.75 & 2.50 & يشرك المعلمين في تحديد الدورات التدريبية التي يحتاجونها في مجال & 18 \\
\hline \multicolumn{2}{|c|}{ متوسطة } & 0.97 & 3.61 & الدرجة الكلية لامتلاك كفايات تكنولوجيا التعليم & \\
\hline
\end{tabular}

يلاحظ من الجدول (3) أن مستوى امتلاك مديري المدارس الحكومية في محافظة عجلون لكفايات

تكنولوجيا التعليم جاء بلدرجة " متوسطة" وبمتوسط حسابي (3.61)، وقد تراوحت المتوسطات الحسابية بين "2.50-

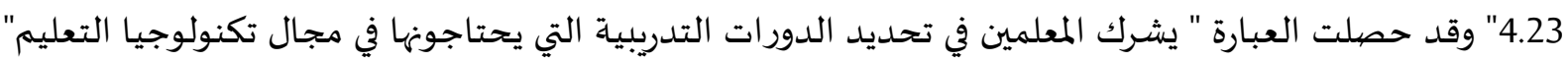
على أقل درجة تقدير بينما حصلت العبارة " يستخدم جهاز عرض البيانات خلال الاجتماعات " على اعلى درجة

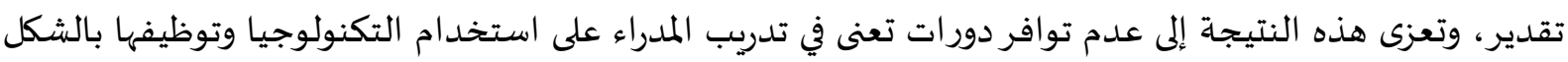

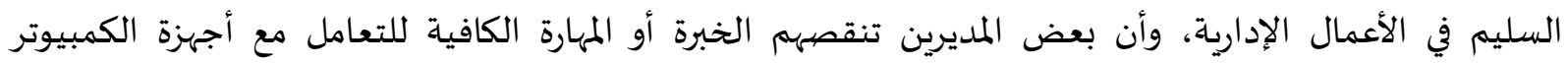

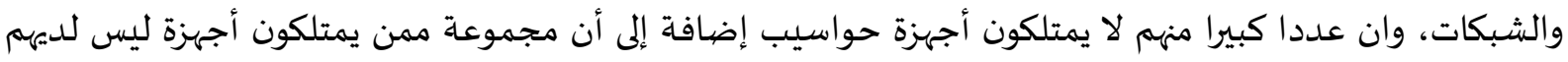

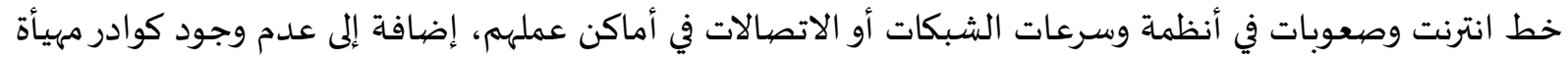
ومدربة على التعامل مع تقنيات تكنولوجيا التعليم.

الإجابة عن السؤال الثاني: " ما مستوى توظيف معلمي المدارس الحكومية في محافظة عجلون لتكنولوجيا

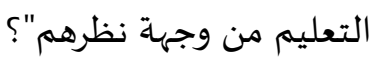

وللإجابة عن السؤال تم استخراج المتوسطات الحسابية والانحرافات المعيارية لإجابات عينة الدراسة والجدول (4) يوضح ذلك.

الجدول (4): المتوسطات الحسابية والانحرافات المعيارية لمستوى توظيف المعلمين لتكنولوجيا التعليم من وجهة نظرهم مرتبة تنازليا

\begin{tabular}{|c|c|c|c|c|c|}
\hline التوظيف مستوى & الرتبة & 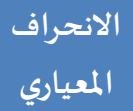 & المتوسط الحسبي & 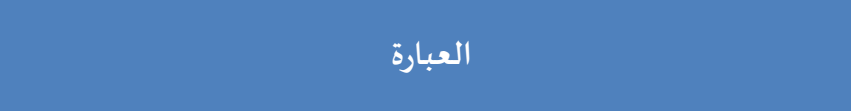 & $\hat{\imath}$ \\
\hline 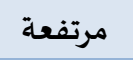 & 1 & 0.38 & 4.35 & أوظف تكنولوجيا التعليم في إجراء الحوار داخل الغرفة الصفية & 5 \\
\hline 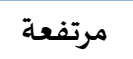 & 2 & 0.44 & 4.33 & أوظف تكنولوجيا التعليم للتنويع في استراتيجيات التعليم & 3 \\
\hline 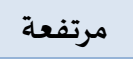 & 3 & 0.43 & 4.30 & أوظف تكنولوجيا التعليم للتنويع في استراتيجيات التعليم & 2 \\
\hline 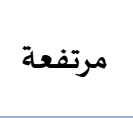 & 4 & 0.54 & 4.27 & أوظف تكنولوجيا التعليم في تنظيم وقت الحصبة لتوزيعه على عناصر & 8 \\
\hline 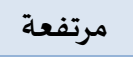 & 5 & 0.49 & 4.15 & أوظف تكنولوجيا التعليم في إعداد الخطط الدراسية & 9 \\
\hline 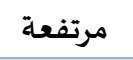 & 6 & 0.99 & 4.09 & أوظف الانترنت في البحث عن مصادر متنوعة للتعلم & 1 \\
\hline 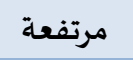 & 7 & 0.90 & 4.05 & أوظف تكنولوجيا التعليم في تنمية مهارات التفكير العليا & 4 \\
\hline 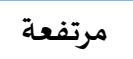 & 8 & 0.79 & 4.02 & أوظف الانترنت للاتصال مع المعلمين من أجل إثراء المنهاج & 6 \\
\hline متوسطة & 9 & 1.26 & 3.67 & أصممم برمجيات تعليمية خاصية لتحقيق أهداف المنهاج & 10 \\
\hline 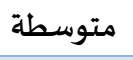 & 10 & 1.22 & 3.55 & أشارك مع المعلمين الاخرين في إعداد الحصص المحوسبة & 7 \\
\hline 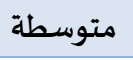 & 11 & 1.41 & 3.52 & أستخدم تكنولوجيا التعليم في تبسيط المعلومات المقدمة للطلبة & 11 \\
\hline 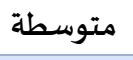 & 12 & 0.85 & 3.49 & أوجه الطلبة لاستخدام الانترنت للبحث عن المعلومات & 15 \\
\hline 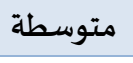 & 13 & 0.92 & 3.35 & أستخدم تكنولوجيا التعليم لزيادة تركيز الطلبة & 12 \\
\hline 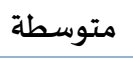 & 14 & 1.01 & 3.30 & أوظف تكنولوجيا التعليم في الاختبارات المدرسية & 14 \\
\hline
\end{tabular}




\begin{tabular}{|c|c|c|c|c|c|}
\hline التوظيف مستوى & 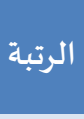 & المعبياري & المتوسطابي & 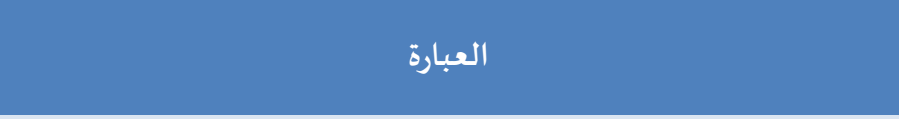 & $\hat{\imath}$ \\
\hline متوسطة & 15 & 1.12 & 3.28 & أوظف تكنولوجيا التعليم في ربط المعرفة العلمية بواقع الطلبة & 17 \\
\hline متوسطة & 16 & 1.07 & 3.21 & أوظف تكنولوجيا التعليم في مراعاة الفروق الفردية بين الطلبة & 20 \\
\hline متوسطة & 17 & 0.87 & 3.18 & أوظف تكنولوجيا التعليم في متابعة أداء الطلبة & 19 \\
\hline متوسطة & 18 & 1.00 & 3.09 & أوظف تكنولوجيا التعليم في إثارة دافعية الطلبة & 13 \\
\hline متوسطة & 19 & 1.04 & 3.05 & أستخدم تكنولوجيا التعليم في الإدارة الصفية & 18 \\
\hline متوسطة & 20 & 1.14 & 2.98 & أشجع الطلبة على تنفيذ مشروعات صغيرة باستخدام تكنولوجيا التعليم & 16 \\
\hline متوسطة & \multicolumn{2}{|c|}{0.89} & 3.66 & \multicolumn{2}{|l|}{ الدرجة الكلية لدرجة توظيف المعلمين لتكنولوجيا التعليم } \\
\hline
\end{tabular}

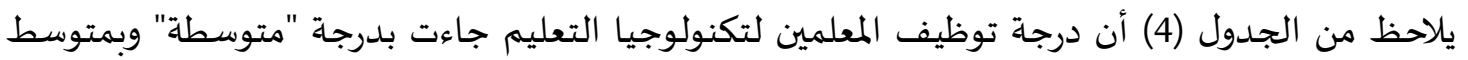

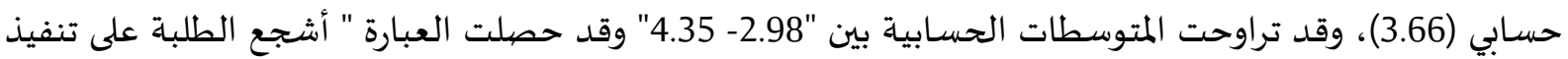

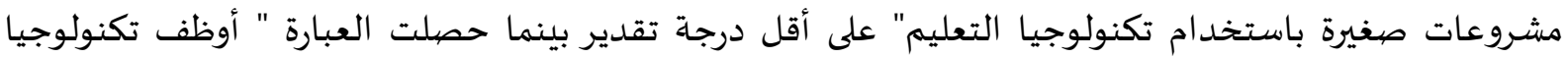
التعليم في إجراء الحوار داخل الغرفة الصفية" على اعلى درجة تقدير، وتعزى هذه النتيجة إلى اكتفاء بعض التصاء المعلمين

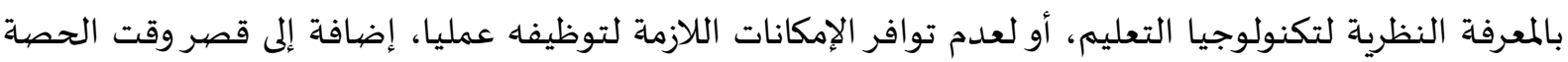

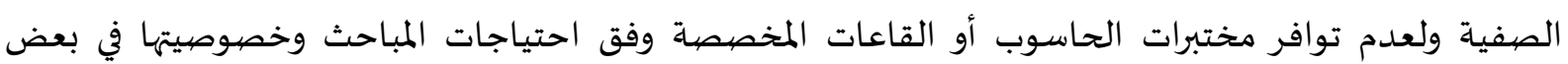
المدارس وخاصة الصغيرة منها، مما يؤدي إلى ضعف توظيف تكنولوجيا التعليم في العملية التعليمياة.

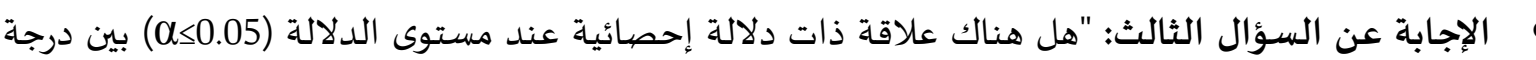
امتلاك مديري المدارس الحكومية في محافظة عجلون لكفايات تكنولوجيا التعليم ودرجة توظيف المعلمين

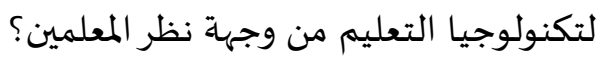

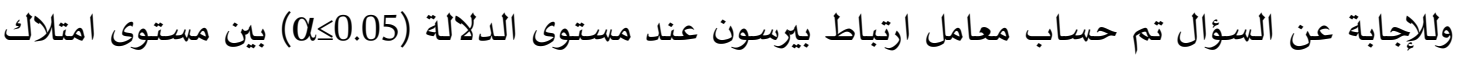

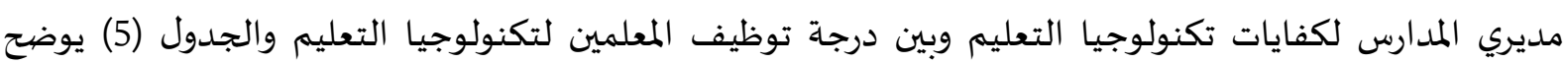

الجدول (5): معامل الارتباط بين مستوى امتلاك مديري المدارس لكفايات تكنولوجيا التعليم وبين درجة توظيف المعلمين لتكنولوجيا التعليم

\section{دوجة توظليف المعلمين لتكنولوجيا التعليم}

$$
\text { *0.186 }
$$$$
0.05
$$

معامل ارتباط بيرسون

مستوى الدلالة
المجال

مستوى امتلاك مديري المدارس

لكفايات تكنولوجيا التعليم

يظهر من الجدول (5) وجود علاقة ذات دلالة احصائية عند مستوى الدلالة (مئ0.05) بين مستوى امتلاك

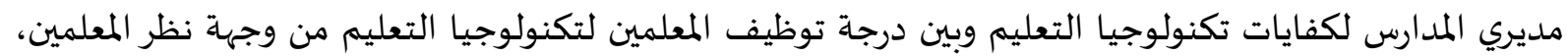
حيث بلغ معامل الارتباط (0.186)، حيث دل معامل الارتباط ان العلاقة بين متغيري الدراسة ( مستوى امتلاك

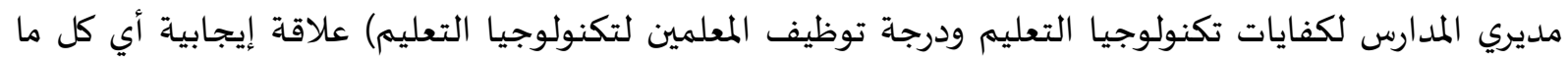

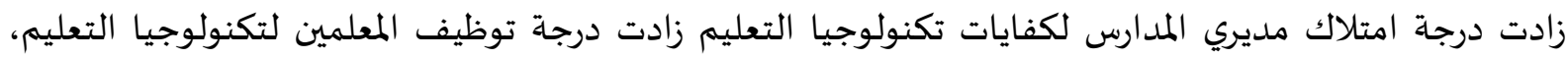

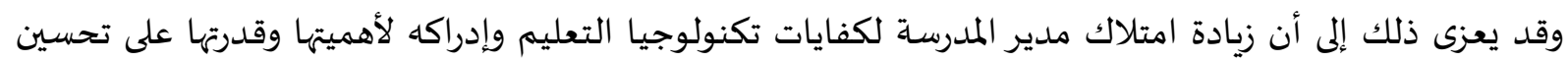

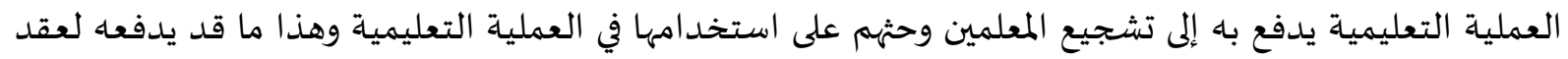

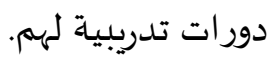




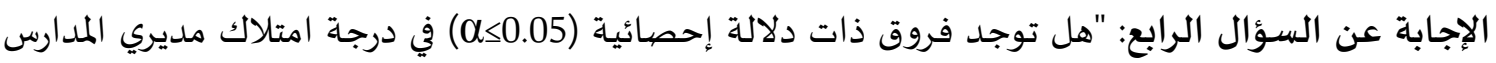

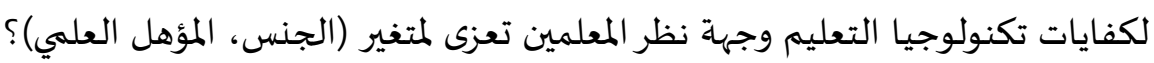

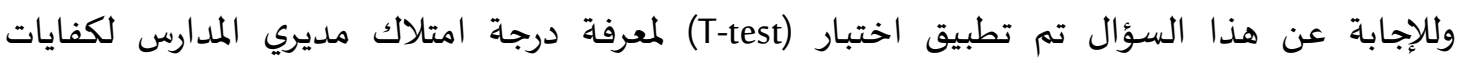

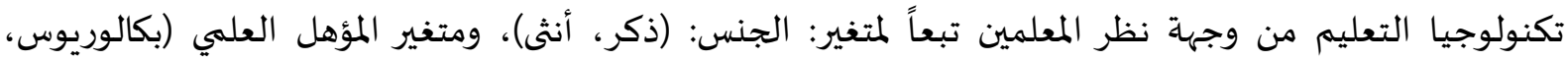
دراسات عليا) والجدول رقم (6) و(7) يبين تلك القيم. الجدول (6): نتائج تطبيق اختبار (t-test) تبعا لمتنغير الجنس

\begin{tabular}{|c|c|c|c|c|c|}
\hline مستوى الدلالة & درجات الحرية & قيمة T & المتوسط الحسابي & فئة المتخير & المتغير \\
\hline \multirow{2}{*}{0.136} & \multirow{2}{*}{338} & \multirow{2}{*}{1.50} & 4.42 & ذكر & \multirow{2}{*}{ الجنس } \\
\hline & & & 4.22 & أنثى & \\
\hline
\end{tabular}

يتضح من الجدول (6) عدم وجود فروق ذات دلالة إحصائية عند مستوى الدلالة (10.05) في درجة

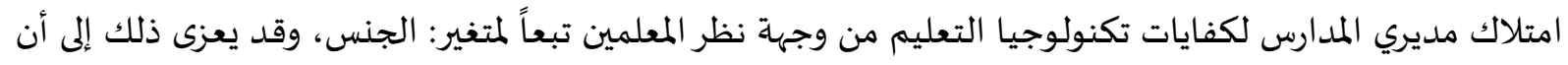
الذكور والإناث قد خضعوا لنفس التدريب فيما يخص تكنولوجيا التعليم، وقد يعزى ذلك أيضا إلى أن الذكور والإناث في مجتمعنا الأردني منفتحين على التكنولوجيا بشكل متساوي.

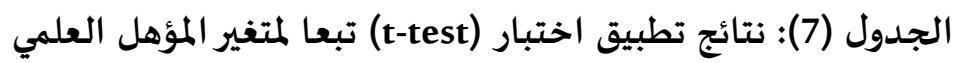

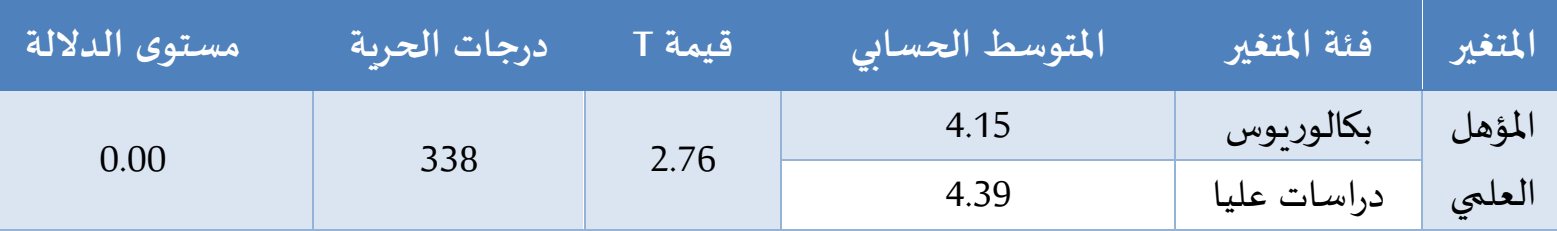

يتضح من الجدول (7) وجود فروق ذات دلالة إحصائية عند مستوى الدلالة (ب0.05) في درجة امتلاك

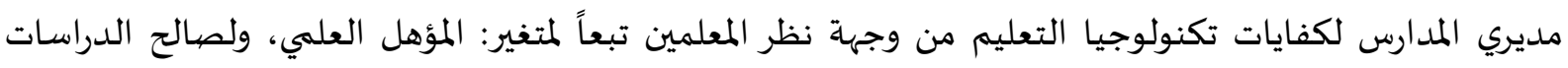

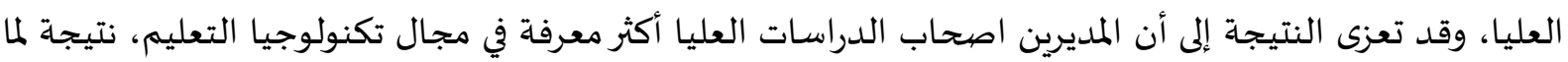

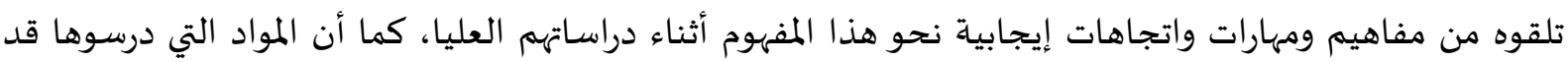
تكون مرتبطة بشكل أكبر بالتعليم التكنولوبي.

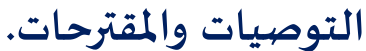

بناءً على النتائج التي توصلت إليها الدراسة توصي الباحثة وتقترح بما يلي:

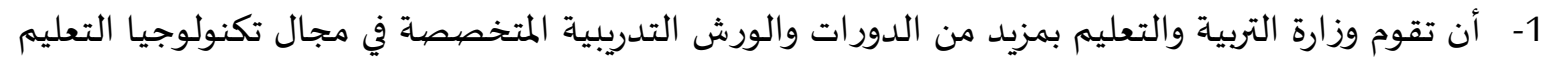
في العملية التربوية لمديري المدارس والمعلمين.

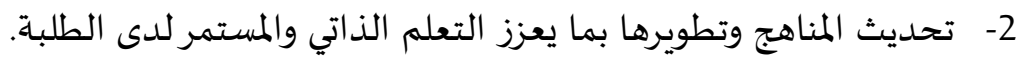
3- ت تحسين البنية التحتية التكنولوجية للمدارس.

4- تعزيز المعلم وتشجيعه على استخدام وسائل تكنولوجيا التعليم في العملية التعليمية.

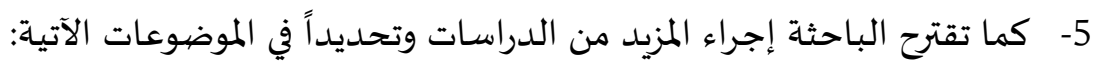
1. إجراء دراسات حول معيقات توظيف تكنولوجيا التعليم في المدارس.

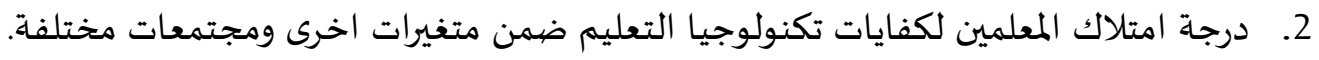


- أبو ربيع، ابتسام؛ والشرمان، عاطف (2015). مستوى إدراك مديري المدارس الأساسية الخاصة لأهمية

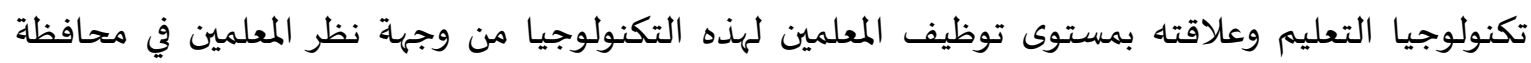
العاصمة عمان. رسالة ماجستير غير منشورة. جامعة الشرق الأوسط.

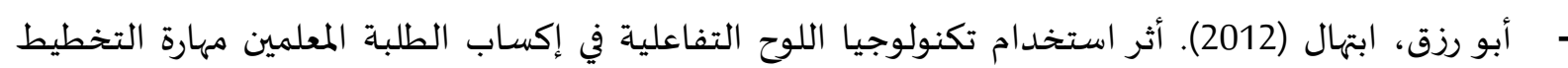
لتدريس مادة اللغة العربية واتجاهاتهم نحوها كأداة تعليمية. المجلة الدولية للأبحاث التربوية. 2 (23). 153-

البادي، رقية (2020). درجة توظيف تكنولوجيا التعليم في العملية التعليمية في مدارس قصبة المفرق من وجهة

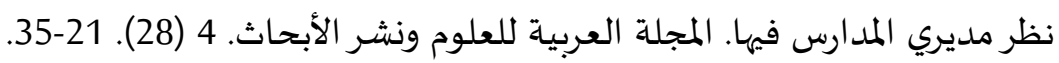
الحربي، هيفاء أحمد (2019). "مفهوم تكنولوجيا التعليم". تكنولوجيا التعليم /

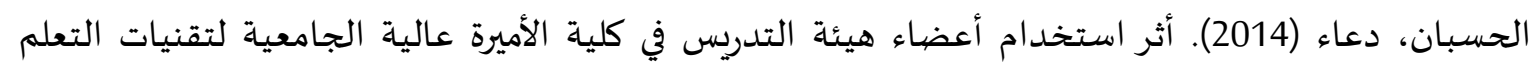

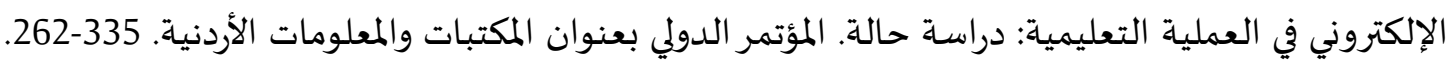

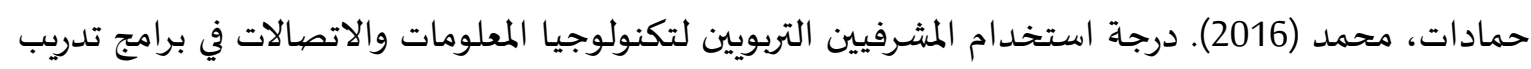
المعلمين في الأردن والصعوبات التي يواجهونها من وجهة نظر المعلمين. دراسات العلوم التربوية. 43 (1). 135-

الحياصات، وفاء (2010). الكفايات التكنولوجية اللازمة للمعلمين ودرجة ممارستهم لها من وجهة نظر مديري المدارس والمشرفين التربويين. مجلة جامعة الأنبار للعلوم الإنسانية. (3). 841-892.

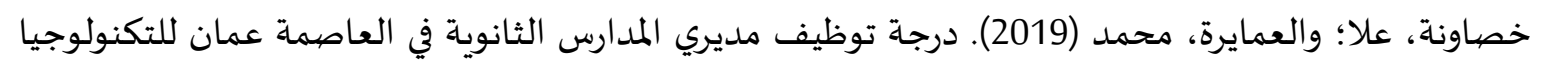
في أداء مهامهم الوظيفية من وجهة نظرهم. دراسات العلوم التربوية. 46 (1). 553-569.

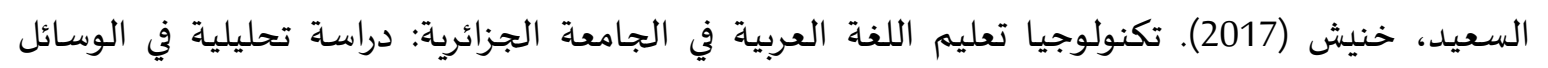
والتقنيات المعتمدة في التعليم. أطروحة دكتوراه غير منشورة. جامعة باتنة 1. الجزائر. سلامة، عبد الحافظ (1998). مدخل إلى تكنولوجيا التعلم. ط1. دار الفكر. عمان، الأردن.

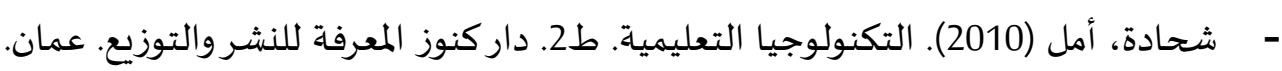
الشديفات، منيرة، والزبون، محمد (2020). واقع توظيف تكنولوجيا التعليم في العملية التعليمية في مدارسيا قصبة المفرق من وجهاة نظر المعلمين فيها. دراسات العلوم التربوية. 47 (1). 242-253.

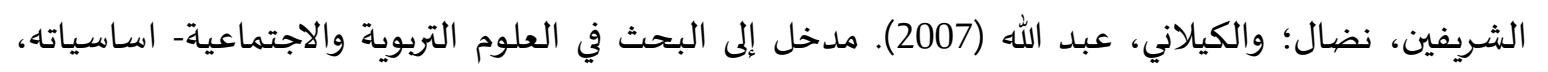

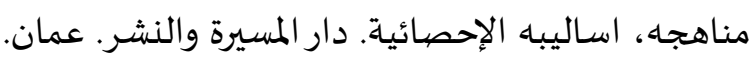
الصرايرة، خالد؛ وأبو حميد، عاطف (2016). دور الإدارة المدرسية في نشر تكنولوجيا المعلومات والاتصالات فئان في دارئ المجتمع المدرسي. دراسات العلوم التربوية. 43 (4). 1483-1501. العزاوي، عبد الرحمن؛ عبود، محمود (2008). مستقبل التربية في الوطن العربي في ضوء المواء الثورة المعلوماتية.

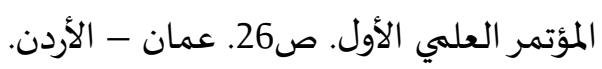
عطير، ربيع (2015). واقع الإدارة الإلكترونية في جامعة فلسطين التقنية خضيوري وسبل تطويرها. المجلة الفلسطينية للتعليم المفتوح. 9 (5). 81-121). 
- العمايرة، محمد (2015). مبادئ الإدارة المدرسية. ط5. دار المسيرة للنشر والتوزيع. عمان.

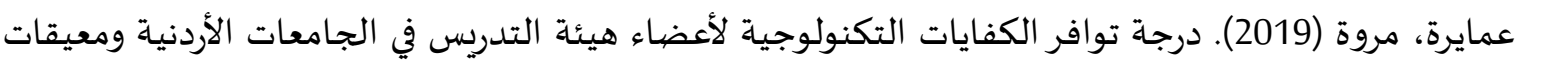
توافرها. رسالة ماجستير غير منشورة. جامعة الشرق الأوسط.

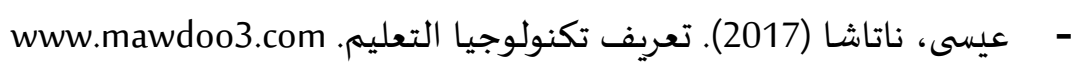

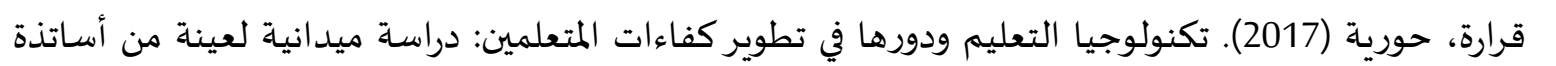

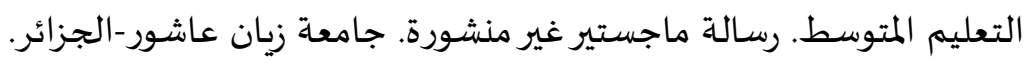
مرعي، توفيق (2005). تكنولوجيا التعليم بين النظرية والتطبيق. دار المسيرة للنشر والتوزيع. عمان. مصطفى، إنتصار (2009). خصائص معلم التربية الإسلامية الفعال في المرحلة الثانوية من وجها نظئة نظر الطلبة.

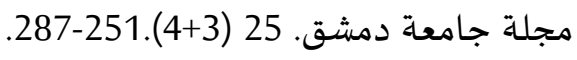

موسى، بلال (2018). الكفايات اللازمة للطلبة المعلمين أثناء إعدادهم لمهنة التدريس بجامعادة البهائة البحر الأحمر.

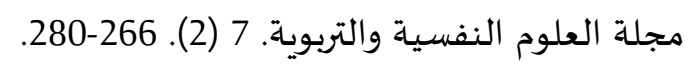

المومني، محمد؛ والسعايدة، منعم (2018). درجة توافر المعايير المهنية لدى معلمي التربية المهنية في محافظة عجلون من وجهة نظر المعلمين أنفسهم ومديريهه. مجلة الجامعة الإسلامية للدراسات التربوية والنفسية. 279 .569-544.(4) - م وزارة التربية والتعليم (2014). تعليمات وصفف وتصنيف الوظائف للمدارس، عمان. وزارة التربية والتعليم (2018). الخطة الاستراتيجية لوزارة التربية والتعليم. www.moe.gov.jo

ثانياً- المراجع بالإنجليزية:

- Baylor, A., Ritchie, D (2002). What factors facilitate teacher skill, teacher morale and perceived student learning in technology using classroom. Computer and Education. 39 (4). 395-414.

- Gumbo, M., Makgato, M., Muller, H (2012). The impact of In- service technology training programs on technology teachers. Journal of technology studies, 38 (1). 23-33.

- Ira, N., Gecer, A., Cloak, I (2019). Detecting the opinion of the secondary administrator regarding the use of mobile technologies for educational Purposes. Educational policy analysis and strategic research. 14 (3). 240-311.

- Oloube, N (2006). The impact of professional and non-professional teacher, ICT competences in secondary school in Nigeria. Journal of Information technology impact. 2 (6). 101-118.

- Robert, B. (2011). An analysis of principals perceptions of technology influence in today's school. (PHD Dissertation). Huston University. USA. 